\title{
Simulation of the intraseasonal variability over the Eastern Pacific ITCZ in climate models
}

\author{
Xianan Jiang • Duane E. Waliser - Daehyun Kim • Ming Zhao - Kenneth R. Sperber • \\ William F. Stern · Siegfried D. Schubert · Guang J. Zhang • Wanqiu Wang • \\ Marat Khairoutdinov $\cdot$ Richard B. Neale $\cdot$ Myong-In Lee
}

Received: 31 March 2011/Accepted: 9 May 2011/Published online: 22 May 2011

(C) Springer-Verlag 2011

\begin{abstract}
During boreal summer, convective activity over the eastern Pacific (EPAC) inter-tropical convergence zone (ITCZ) exhibits vigorous intraseasonal variability (ISV). Previous observational studies identified two dominant ISV modes over the EPAC, i.e., a 40-day mode and a quasi-biweekly mode (QBM). The 40-day ISV mode is generally considered a local expression of the MaddenJulian Oscillation. However, in addition to the eastward propagation, northward propagation of the 40-day mode is also evident. The QBM mode bears a smaller spatial scale than the 40-day mode, and is largely characterized by northward propagation. While the ISV over the EPAC exerts significant influences on regional climate/weather systems, investigation of contemporary model capabilities in representing these ISV modes over the EPAC is limited.
\end{abstract}

X. Jiang

Joint Institute for Regional Earth System Science and

Engineering, University of California, Los Angeles, CA, USA

X. Jiang $(\bowtie) \cdot$ D. E. Waliser

Jet Propulsion Laboratory, California Institute of Technology,

MS 183-501, 4800 Oak Grove Drive, Pasadena, CA 91109, USA

e-mail: xianan@jifresse.ucla.edu

D. Kim

Lamont-Doherty Earth Observatory of Columbia University,

New York, NY, USA

M. Zhao · W. F. Stern

NOAA/Geophysical Fluid Dynamics Laboratory,

Princeton, NJ, USA

K. R. Sperber

Lawrence Livermore National Laboratory, Livermore, CA, USA

S. D. Schubert

NASA Goddard Space Flight Center, Greenbelt, MD, USA
In this study, the model fidelity in representing these two dominant ISV modes over the EPAC is assessed by analyzing six atmospheric and three coupled general circulation models (GCMs), including one super-parameterized GCM (SPCAM) and one recently developed high-resolution GCM (GFDL HIRAM) with horizontal resolution of about $50 \mathrm{~km}$. While it remains challenging for GCMs to faithfully represent these two ISV modes including their amplitude, evolution patterns, and periodicities, encouraging simulations are also noted. In general, SPCAM and HIRAM exhibit relatively superior skill in representing the two ISV modes over the EPAC. While the advantage of SPCAM is achieved through explicit representation of the cumulus process by the embedded 2-D cloud resolving models, the improved representation in

G. J. Zhang

Scripps Institution of Oceanography, La Jolla, CA, USA

W. Wang

NOAA/National Centers for Environmental Prediction,

Camp Springs, MD, USA

M. Khairoutdinov

Institute for Terrestrial and Planetary Atmospheres,

Stony Brook University, Stony Brook, NY, USA

R. B. Neale

National Center for Atmospheric Research, Boulder, CO, USA

M.-I. Lee

Ulsan National Institute of Science and Technology, Seoul, South Korea 
HIRAM could be ascribed to the employment of a strongly entraining plume cumulus scheme, which inhibits the deep convection, and thus effectively enhances the stratiform rainfall. The sensitivity tests based on HIRAM also suggest that fine horizontal resolution could also be conducive to realistically capture the ISV over the EPAC, particularly for the QBM mode. Further analysis illustrates that the observed 40-day ISV mode over the EPAC is closely linked to the eastward propagating ISV signals from the Indian Ocean/ Western Pacific, which is in agreement with the general impression that the 40-day ISV mode over the EPAC could be a local expression of the global Madden-Julian Oscillation (MJO). In contrast, the convective signals associated with the 40-day mode over the EPAC in most of the GCM simulations tend to originate between $150^{\circ} \mathrm{E}$ and $150^{\circ} \mathrm{W}$, suggesting the 40-day ISV mode over the EPAC might be sustained without the forcing by the eastward propagating MJO. Further investigation is warranted towards improved understanding of the origin of the ISV over the EPAC.

Keywords Intraseasonal variability $\cdot$ Eastern Pacific warm pool $\cdot$ ITCZ

\section{Introduction}

Intraseasonal variability (ISV) plays a significant role in the tropical atmosphere (see Lau and Waliser 2005; Zhang 2005 for a thorough review). While the strongest ISV is found to be associated with the Asian monsoon, vigorous intraseasonal variations with a dominant period of 30-50 days (hereafter the 40-day ISV mode) in winds and convection have also been widely reported over the eastern Pacific inter-tropical convergence zone (ITCZ) during boreal summer (e.g., Knutson and Weickmann 1987; Kayano and Kousky 1999; Maloney and Hartmann 2000a; Maloney and Esbensen 2003, 2007; de Szoeke and Bretherton 2005; Jiang and Waliser 2008, 2009; and many others). This 40-day ISV mode over the eastern Pacific (EPAC) is mainly characterized by eastward propagation, and is largely considered a local expression of the global Madden-Julian Oscillation (MJO; Madden and Julian 1994). In addition to the eastward propagating component, northward migration of this ISV mode over the EPAC, noted by Jiang and Waliser (2008) and Maloney et al. (2008), exhibits a strong resemblance to its counterpart over the Asian summer monsoon region (Jiang et al. 2004).

In addition to the 40-day ISV mode, a recent study by Jiang and Waliser (2009), based on an extended empirical orthogonal function (EEOF) analysis of rainfall data from the Tropical Rainfall Measuring Mission (TRMM), also suggested a second ISV mode over the EPAC ITCZ with a period of about 16 days (hereafter a quasi-biweekly mode; QBM).
While quasi-biweekly oscillations have been widely reported in many other areas (e.g., Asian monsoon region: Krishnamurti and Bhalme 1976; Chen and Chen 1993; Fukutomi and Yasunari 1999; African monsoon: Janicot and Sultan 2001; Sultan et al. 2003; Maloney and Shaman 2008; North America monsoon: Mullen et al. 1998; Kiladis and Hall-McKim 2004; Jiang and Lau 2008; Wu et al. 2009; South America: Paegle et al. 2000), this high-frequency QBM ISV mode associated with the EPAC ITCZ has received little attention possibly due to an insufficiently long period of high-resolution observations over this region. The analysis by Jiang and Waliser (2009) further indicates that the QBM over the EPAC is largely characterized by a northward propagation.

The ISV over the EPAC exerts significant influences on regional weather and climate, including tropical cyclone activity over the EPAC and the Gulf of Mexico (e.g., Maloney and Hartmann 2000a, b; Molinari and Vollaro 2000; Higgins and Shi 2001; Aiyyer and Molinari 2008; Barrett and Leslie 2009), the summertime wind jets in the Gulfs of Tehuantepec and Papagayo (Maloney and Esbensen 2003), the Caribbean Low-Level Jet (Serra et al. 2010) and precipitation (Martin and Schumacher 2010), the mid-summer drought over Central America and Mexico (Magana et al. 1999; Small et al. 2007), the North American monsoon (Higgins and Shi 2001; Lorenz and Hartmann 2006; Wu et al. 2009), and possibly the El Nino evolution (Vintzileos et al. 2005). Furthermore, if the predictability of the EPAC ISV is similar to the MJO (about 2-4 weeks; Waliser 2006; Jiang et al. 2008), a better understanding of the ISV over the EPAC would greatly benefit the improved predictive skill for regional climate.

The study of the capability of general circulation models (GCMs) to represent the MJO has been the subject of widespread interest in the climate research community (e.g., Slingo et al. 1996, 2005; Lin et al. 2006; Kim et al. 2009). However, much less effort has been placed on the assessment of GCM simulations of the ISV over the EPAC. Lin et al. (2008b) analyzed simulations of the North American Monsoon in conjunction with the ISV and easterly waves over the EPAC by the 22 Coupled Model Intercomparison Project-3 (CMIP3) models used in Intergovernmental Panel on Climate Change (IPCC) Fourth Assessment Report (AR4). Their results indicate that most of the IPCC AR4 GCMs tend to underestimate the variances of the ISV over the EPAC. Meanwhile, these models also poorly capture the eastward propagation of the observed ISV. By using a regional coupled model, a recent study by Small et al. (2011) illustrates that both the MJO forcing from the west and local convection-circulation feedbacks are important for the ISV over the EPAC, whereas the air-sea coupling only plays a minor role.

In the present study, we examine model capabilities in simulating the ISV over the EPAC in nine GCMs. In eight 
of the nine models analyzed herein, MJO variability was evaluated by the Climate Variability and Predictability (CLIVAR) MJO Working Group (Kim et al. 2009), using a standardized diagnostic approach (MJOWG; Kim et al. 2009; US CLIVAR Madden-Julian Oscillation Working Group 2009). Most of these models have recently been updated since the IPCC AR4, including one super-parameterized AGCM (SPCAM), which utilizes embedded 2-D cloud-resolving models (CRMs) instead of conventional cumulus parameterization (Khairoutdinov et al. 2005), and an operational forecast model (CFS; Saha et al. 2006) at the National Oceanic and Atmospheric Administration (NOAA). The ninth model analyzed herein is a new high resolution atmospheric model (HIRAM; Zhao et al. 2009), developed at NOAA's Geophysical Fluid Dynamics Laboratory (GFDL). We will evaluate how well the two leading ISV modes over the EPAC are represented in these models.

The organization of this paper is as follows. The models and observational datasets used for this study are briefly described in Sect. 2. In Sect. 3, summer mean state and ISV variances over the EPAC simulated by the GCMs are inspected. In Sect. 4, we focus on examining how well the observed two leading ISV modes are represented in the GCMs. Finally, a summary and a discussion are presented in Sect. 5.

\section{Participating models and observational datasets}

A brief description of the nine models used in this study, including model names, horizontal and vertical resolutions, and integration period, is given in Table 1. Note that while the sub-grid cumulus processes in the parent GCM of SPCAM are explicitly represented based on the embedded 2-D CRMs, they are parameterized based on mass-flux-type schemes in all other eight conventional GCMs, in which clouds are represented by single or multiple updrafts and downdrafts with the assumption of steady-state clouds. More details of the three coupled (CFS, CM2.1, ECHAM4/OPYC) and five uncoupled (CAM3.5, CAM3z, GEOS5, ${ }^{1}$ SNU, SPCAM) GCMs participating the MJOWG model comparison can be found in Kim et al. (2009), and also from the website: http://climate.snu.ac.kr/mjo_diagnostics/index.htm.

In addition to the eight models employed by Kim et al. (2009), simulations based on the GFDL HIRAM are also analyzed in this study. The HIRAM was recently developed based on the standard version of GFDL AGCM (AM2; Anderson et al. 2004), i.e., the atmospheric component of the GFDL CM2.1, to improve the deficiency in the AM2 in

\footnotetext{
${ }^{1}$ Note that the GEOS5 model used to produce the simulation analyzed here is essentially the same model used in the production of the Modern Era Retrospective-Analysis for Research and Applications (MERRA; Bosilovich et al. 2006), though is run here at coarser resolution
}

simulating tropical transient activity (Zhao et al. 2009). This model has been used in studies of hurricane interannual variability, multi-decadal trends, responses to 21 st century warming as well as seasonal hurricane predictions for both N. Atlantic and E. Pacific (Zhao and Held 2010; Zhao et al. 2010). The major changes in the HIRAM to the AM2 include: employment of a finite-volume core based on a cubed-sphere grid instead of a longitude-latitude grid in the AM2; an increase of the vertical levels from 24 to 32, with extra vertical resolution particularly near the tropopause; replacement of the prognostic cloud fraction scheme following Tiedtke (1993) in the AM2 with a simpler assumption concerning the PDF of total cloud water; and replacement of the relaxed Arakawa-Schubert convective closure in AM2.1 with a strongly entraining plume scheme following the parameterization of shallow convection by Bretherton et al. (2004). For more details on HIRAM, readers are referred to Zhao et al. (2009). The horizontal resolution of the standard version of HIRAM is about $50 \mathrm{~km}$. In order to further investigate the dependence of the ISV simulation over the EPAC on the model horizontal resolution, we also analyze output from an additional run based on HIRAM but with a reduced horizontal resolution of about $\sim 2.5^{\circ}$ (hereafter HIRAM-lores). This horizontal resolution is comparable to those in most of the other GCMs analyzed in this study.

Note that all the six AGCMs analyzed here are forced by observed monthly mean sea surface temperature (SST) during the periods listed in Table 1. Daily output of rainfall and $850 \mathrm{hPa}$ wind fields over the EPAC from the above nine models are analyzed and compared to observations including the mean state and intraseasonal variances. Rainfall observations are based on Tropical Rainfall Measuring Mission (TRMM, version 3B42; Huffman et al. 1995) during the period from 1998 to 2008 . TRMM 3B42 rainfall is a global precipitation product based on multi-satellite and rain gauge analysis. It provides precipitation estimates with 3-hourly temporal resolution on a 0.25 -degree spatial resolution in a global belt extending from $50^{\circ} \mathrm{S}$ to $50^{\circ} \mathrm{N}$. The raw TRMM rainfall is interpolated onto $1^{\circ}$ by $1^{\circ}$ daily data. Daily wind fields during the same period of the TRMM rainfall are obtained from the recent European Centre for MediumRange Weather Forecasts (ECMWF) reanalysis, e.g., ERAInterim (Simmons et al. 2006; hereafter ERA-I reanalysis), with a horizontal resolution of $1.5^{\circ}$ by $1.5^{\circ}$.

\section{Summer mean state and ISV variances simulated by GCMs}

\subsection{Summer mean state}

Figure 1 depicts observed and simulated summer mean rainfall (shaded) and $850 \mathrm{hPa}$ winds (vectors) over the 
Table 1 Participating models and brief descriptions

\begin{tabular}{|c|c|c|c|c|c|}
\hline Model & Horizontal resolution & $\begin{array}{l}\text { Vertical } \\
\text { resolution }\end{array}$ & Cumulus scheme & Period & Reference \\
\hline CAM3.5 (NCAR) & $1.9^{\circ}$ lat $\times 2.5^{\circ}$ lon & 26 & $\begin{array}{l}\text { Mass flux (Zhang and Mcfarlane } \\
\text { 1995) }\end{array}$ & $\begin{array}{l}20 \text { years } 1 \text { Jan } \\
1986-31 \text { Dec } 2005\end{array}$ & Neale et al. (2008) \\
\hline CAM3z (SIO) & $\mathrm{T} 42\left(2.8^{\circ}\right)$ & 26 & $\begin{array}{l}\text { Mass flux (Zhang and Mcfarlane } \\
\text { 1995) }\end{array}$ & $\begin{array}{l}15 \text { years } 29 \text { Jan } \\
1980-23 \text { Jul } 1995\end{array}$ & Zhang and $\mathrm{Mu}(2005)$ \\
\hline CFS (NCEP) & T62 $\left(1.8^{\circ}\right)$ & 64 & Mass flux (Hong and Pan 1998) & 20 years & Wang et al. (2005) \\
\hline CM2.1 (GFDL) & $2^{\circ}$ lat $\times 2.5^{\circ}$ lon & 24 & $\begin{array}{l}\text { Mass flux (Moorthi and Suarez } \\
\text { 1992) }\end{array}$ & 20 years & Delworth et al. (2006) \\
\hline $\begin{array}{l}\text { ECHAM4/OPYC } \\
\text { (MPI via PCMDI) }\end{array}$ & $\mathrm{T} 42\left(2.8^{\circ}\right)$ & 19 & $\begin{array}{l}\text { Mass flux (Tiedtke 1989; Nordeng } \\
\text { 1994) }\end{array}$ & 20 years & $\begin{array}{l}\text { Roeckner et al. (1996), } \\
\text { Sperber et al. (2005) }\end{array}$ \\
\hline GEOS5 (NASA) & $1^{\circ}$ lat $\times 1.25^{\circ}$ lon & 72 & $\begin{array}{l}\text { Mass flux (Moorthi and Suarez } \\
\text { 1992) }\end{array}$ & $\begin{array}{l}12 \text { years } 1 \text { Dec } \\
1993-30 \text { Nov } 2005\end{array}$ & Rienecker et al. (2008) \\
\hline SNU-AGCM (SNU) & $\mathrm{T} 42\left(2.8^{\circ}\right)$ & 20 & Mass flux (Numaguti et al. 1995) & $\begin{array}{l}20 \text { years } 1 \text { Jan } \\
1986-31 \text { Dec } 2005\end{array}$ & Lee et al. (2003) \\
\hline SPCAM (CSU) & $\mathrm{T} 42\left(2.8^{\circ}\right)$ & 26 & $\begin{array}{l}\text { Super-parameterization } \\
\text { (Khairoutdinov and Randall } \\
\text { 2001) }\end{array}$ & $\begin{array}{l}19 \text { years } 1 \text { Oct } \\
1985-25 \text { Sep } 2005\end{array}$ & $\begin{array}{l}\text { Khairoutdinov et al. } \\
\text { (2005) }\end{array}$ \\
\hline $\begin{array}{l}\text { HIRAM (GFDL) } \\
\text { HIRAM-lores }\end{array}$ & $\begin{array}{l}0.5^{\circ} \text { lat } \times 0.6^{\circ} \text { lon } \\
2.0^{\circ} \text { lat } \times 2.5^{\circ} \text { lon }\end{array}$ & 32 & Mass flux (Bretherton et al. 2004) & $\begin{array}{l}19 \text { years } 1 \text { Jan } \\
1990-31 \text { Dec } 2008\end{array}$ & Zhao et al. (2009) \\
\hline
\end{tabular}

EPAC. The observed summer mean rainfall over the EPAC (Fig. 1a) is largely characterized by the elongated rain belt along the ITCZ near $10^{\circ} \mathrm{N}$, and a broad rain zone at the far eastern end of the EPAC, known as the EPAC warm pool. Rainfall signals over Central America and Mexico are also seen with a northwestward extension along Sierra Madre Occidental off the Gulf of California (GoC), representing the core region of the North American monsoon (NAM). Meanwhile, rainfall over South American continent is also observed. Accompanying this rainfall pattern, the most prominent feature in the observed $850 \mathrm{hPa}$ wind fields over the EPAC is the convergent flow at the ITCZ, namely, the northeasterly winds to the north, and the southeasterly winds and cross-equatorial flow to the south of the ITCZ.

All the GCMs generally capture the bulk features of the ITCZ rain belt and the NAM, although most of the models tend to overestimate the rainfall amplitude, particularly over the coastal region near Panama. Two models, ECHAM4/OPYC and SNU, show a discontinuous ITCZ belt near $120^{\circ} \mathrm{W}$. HIRAM simulates well the spatial pattern of mean rainfall but with too strong amplitude. The mean rainfall patterns simulated in the two versions of HIRAM are largely similar; the improvement of the NAM rainfall is discernible in the high resolution run. Generally, among the nine models, SPCAM displays relatively better simulations of the observed ITCZ rainfall in terms of both amplitude and pattern. However, the rainfall over South America is underestimated in SPCAM; in contrast, it is too strong in GEOS5.
While these GCMs are largely capable of simulating the mean rainfall pattern, most of them exhibit large deficiencies in simulating the observed convergent flow at $850 \mathrm{hPa}$ associated with the ITCZ. In particular, the southerly cross-equatorial flow is not simulated in most of the GCMs except ECHAM4/OPYC, CFS and GEOS5. Given that these deficiencies are evident in both AGCMs and CGCMs, and also in both high and low-resolution versions of HIRAM, the air-sea coupling and horizontal resolution may not explain why observed convergent flow at $850 \mathrm{hPa}$ is poorly simulated. Further inspection of the vertical wind structures in HIRAM shows that this model represents both the deep and shallow overturning Hadley cells over the EPAC as described by Zhang et al. (2004), although the simulated southerly cross-equatorial flow is mainly confined below $850 \mathrm{hPa}$ (not shown). In contrast, in ERA-I reanalysis, this southerly flow extends higher in the atmosphere $(800 \mathrm{hPa})$, suggesting deficiencies in the PBL schemes in GCMs.

\subsection{0-90 day Intraseasonal variances}

Figure 2 illustrates the standard deviation of 10- to 90-day band-pass filtered rainfall anomalies during boreal summer based on TRMM observations (Panel a) and model simulations (Panels $\mathrm{b}-\mathrm{k}$ ), which are often used to delineate the amplitude of the ISV activity. Note that in order to eliminate the potential influences of the horizontal resolution, rainfall fields based on all these datasets are interpolated 
Fig. 1 Observed and model simulated summer mean (MayOctober) rainfall patterns (shaded; see color bar at the bottom with units of $\mathrm{mm} \mathrm{day}^{-1}$ ) and $850 \mathrm{hPa}$ winds (vectors; $\mathrm{m} \mathrm{s}^{-1}$ ). Wind vectors are plotted on every three grid points in both $\mathrm{x}$, $\mathrm{y}$ directions in observations, and on every four, six, and two grid points in GEOS5, HIRAM, and other GCMs, respectively (b) САМ 3.5

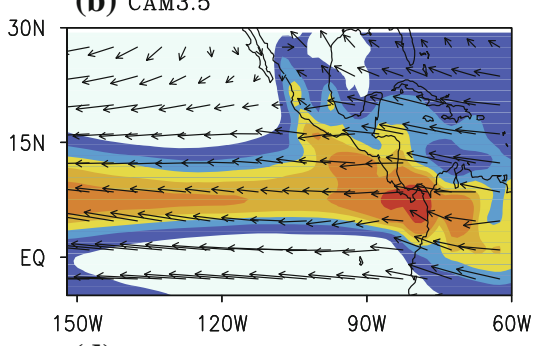

(d) CAM3z

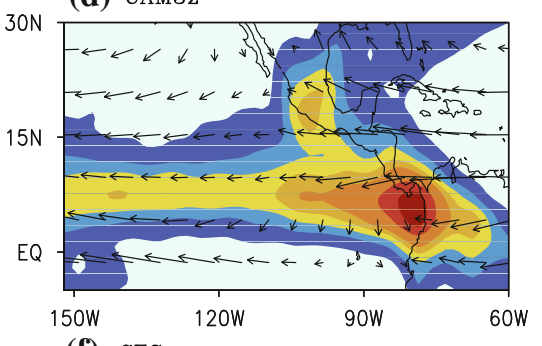

(f) $\mathrm{CFS}$

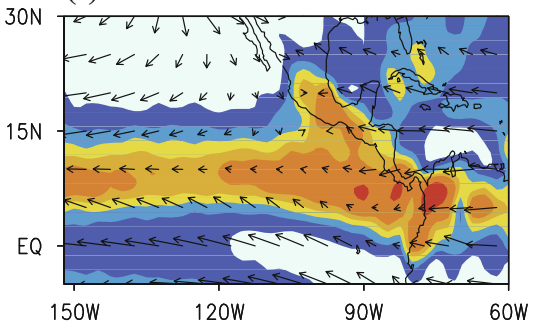

(h) CM2.1

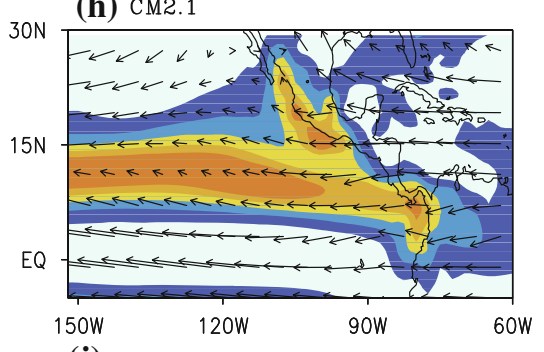

(j) HIRAM

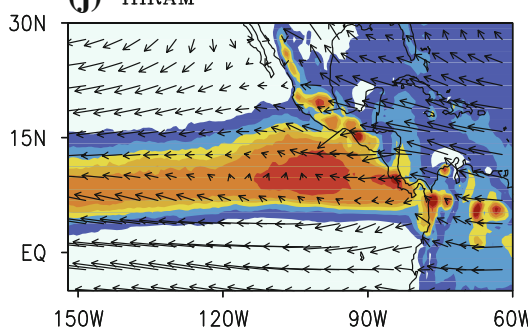

(c) ECHAM_OPYC

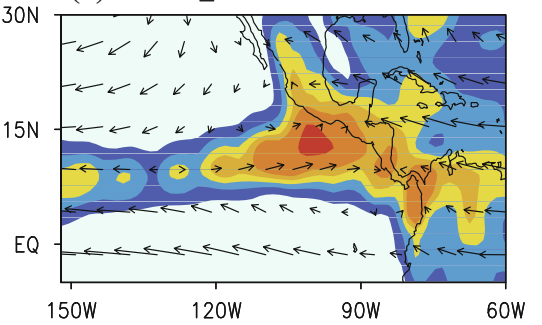

(e) GEOS5

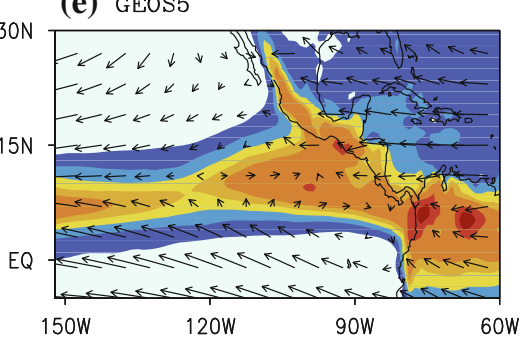

(g) $\mathrm{SNU}$

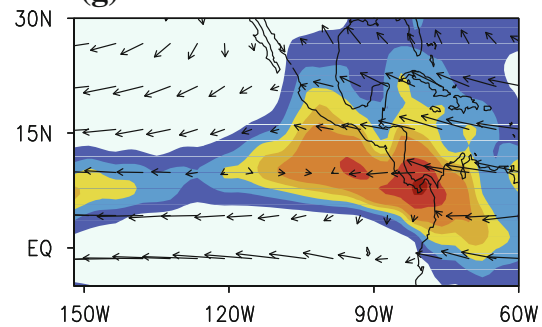

(i) SPCAM

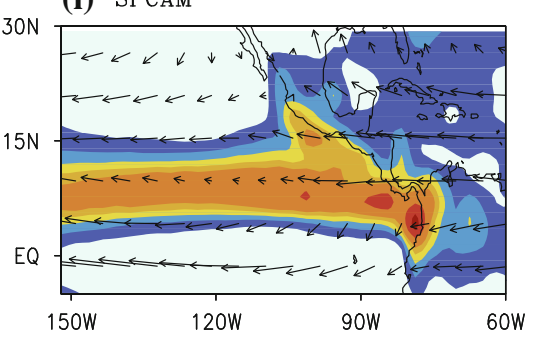

(k) HIRAM-lores

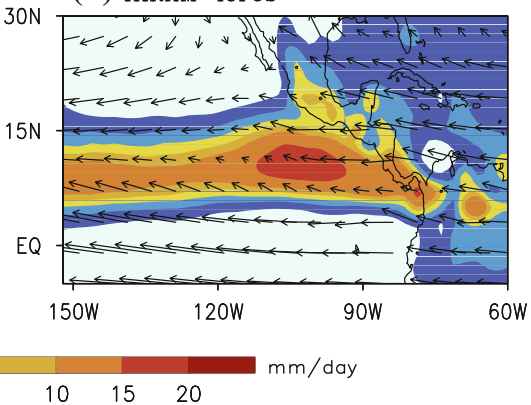


onto the same $2.5^{\circ} \times 2.5^{\circ}$ grids before calculating the standard deviations. The distribution of the observed ISV activity largely follows its summer mean rainfall pattern in Fig. 1a. The maximum activity center is observed near $10^{\circ} \mathrm{N}$ between $120^{\circ} \mathrm{W}$ and $90^{\circ} \mathrm{W}$ over the EPAC. The maximum amplitude of the ISV is underestimated in CAM3.5 and CM2.1 to some degree, and overestimated in CAM3z, CFS, ECHAM4/OPYC, and the two HIRAM runs. In CAM3z, an unrealistic ISV maximum extends from the east coast of Mexico to the EPAC. In SPCAM, the amplitude of the ISV over the EPAC is mostly comparable to the observations, although the maximum ISV activity appears in the coastal region instead of in the EPAC ITCZ in the observations, and it underestimates the ISV variance over South America and Caribbean Sea. In spite of having too strong ISV variance, both HIRAM runs (Fig. 2j-k) capture well the observed spatial distribution of ISV activities. The weakening of the ISV amplitude with a decrease of the model horizontal resolution by HIRAM is noted by comparing the HIRAM and the HIRAM-lores simulations. Note that in addition to uncertainties in physical parameterization schemes, biases in simulated SST patterns could also be responsible for the deficiencies in the mean state and ISV variance patterns in the coupled GCM runs. For example, the too strong ISV activity over the eastern Pacific in CFS is partially due to local warm SST biases in this coupled run (Wang and Seo 2009). The underestimated summer mean rainfall and ISV activity over the ITCZ near $130^{\circ} \mathrm{W}$ in ECHAM/OPYC could be related to small cold SST biases over this region.

Model skill in simulating summer mean rainfall pattern and the ISV variances over the EPAC is summarized in Fig. 3 by showing pattern correlations of mean rainfall between observations and GCM simulations on the $\mathrm{x}$-axis and relative domain-averaged standard deviation amplitudes in GCMs to the observations on the y-axis. Both pattern correlation and domain-averaged amplitudes are derived over $150^{\circ} \mathrm{W}-60^{\circ} \mathrm{W}, 5^{\circ} \mathrm{S}-30^{\circ} \mathrm{N}$. The dark "star" mark in Fig. 3 represents observations. SPCAM, HIRAM, and GEOS5 exhibit relatively higher correlation scores in simulating the mean rainfall pattern than other GCMs. The amplitude of the ISV in SPCAM is largely comparable to the observations. While ISV activity is too active in CFS, HIRAM, and CAM3z, it is too weak in the other five GCMs.

\section{Representation of the two leading ISV modes over the EPAC in GCMs}

In this section, we will examine how the two observed ISV modes, namely, the 40-day mode and the QBM, are represented in the GCMs. The approach to identify the leading
ISV modes in both observations and each model is based on an EEOF analysis (Weare and Nasstrom 1982) of rainfall over the $\mathrm{EPAC}\left(140^{\circ} \mathrm{W}-90^{\circ} \mathrm{W}\right.$; EQ- $\left.30^{\circ} \mathrm{N}\right)$ following Jiang and Waliser (2009; hereafter JW09). Prior to the EEOF analysis, 3-day mean anomalous rainfall data (nonoverlapping) are calculated from the daily 10-90 day bandpass filtered anomalies for both the TRMM observations and GCM simulations. Differing from the previous study of JW09 in which the rainfall data during all seasons were analyzed, in this study the EEOF analysis is only performed for boreal summer rainfall (May-October). The EEOF analysis is conducted with 9 temporal lags of the 3-day mean anomalous data.

Figure 4 illustrates percentages of variances explained by ten leading EEOF modes based on observations and model simulations, where error bars are determined based on the formula by North et al. (1982). Similar to JW09, each of the two leading ISV modes over the EPAC based on observed rainfall is represented by a pair of EEOF modes in quadrature with each other, suggesting the propagating nature of these ISV modes; namely, the first (second) pair of the EEOFs represents the first (second) leading ISV mode. The evolution patterns of anomalous rainfall and $850 \mathrm{hPa}$ winds associated with the two observed leading ISV modes are depicted in Figs. 7a and 10a, respectively, which were derived by lag-regression of these fields versus the standardized time series for the $\mathrm{EEOF}_{1}$ and $\mathrm{EEOF}_{3}$. Since the ISV over the EPAC is rather damped during boreal winter due to local cold SSTs by strong gap winds (e.g., Xie et al. 2005), the leading EEOF patterns of the TRMM rainfall derived here greatly resemble those in JW09.

To identify model counterparts of the two observed leading ISV modes, pattern correlations are calculated between each of the first ten leading EEOF modes from each model simulation and observed $\mathrm{EEOF}_{1} / \mathrm{EEOF}_{3}$. Prior to calculations of the pattern correlation, all the EEOFs based on both the observations and GCMs are interpolated onto 2.5 -by-2.5-degree grids covering $140^{\circ} \mathrm{W}-90^{\circ} \mathrm{W}$, and EQ- $30^{\circ} \mathrm{N}$. Since the EEOF analysis is based on 3-day mean anomalous rainfall data with nine temporal lags, each of the obtained EEOFs consists of evolution patterns with nine sequential time steps, say from time -4 to +4 lags, with an interval of 3 days between neighboring time lags. To consider the possible phase differences between the EEOFs based on each dataset, which is not unexpected, lead/lag pattern correlations of the model EEOFs against the observations are calculated. Therefore, evolution patterns of observed $\mathrm{EEOF}_{1} / \mathrm{EEOF}_{3}$ from time -3 to time +3 (e.g., a total of seven 2-D patterns with a duration of 21 days) are taken as a reference and pattern correlations are calculated against each leading EEOF based on the GCM which also contains seven of the total nine sequential 
Fig. 2 Standard deviation of 10-90-day band-pass filtered summertime (May-October) rainfall based on observations and model simulations (unit: $\mathrm{mm} \mathrm{day}^{-1}$ ). Note that in order to eliminate the potential influences of the horizontal resolution, the standard deviations are calculated on the same $2.5^{\circ}$ by $2.5^{\circ}$ grids in all these datasets

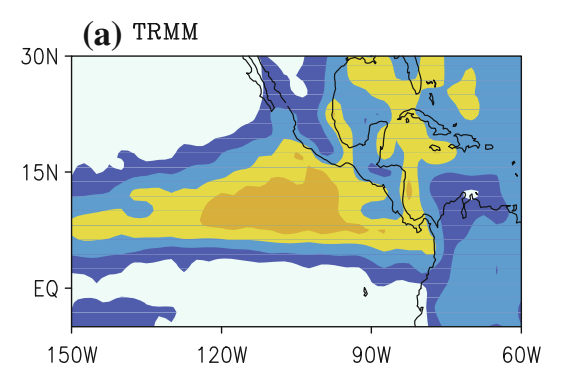

(b) CAM3.5

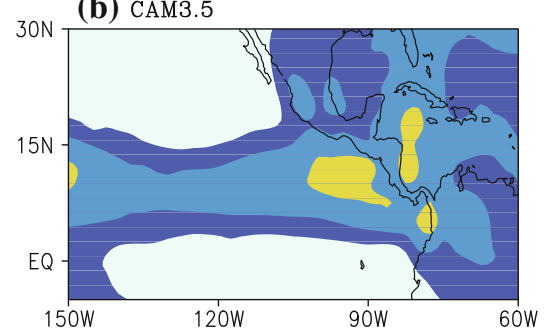

(d) CAM3z

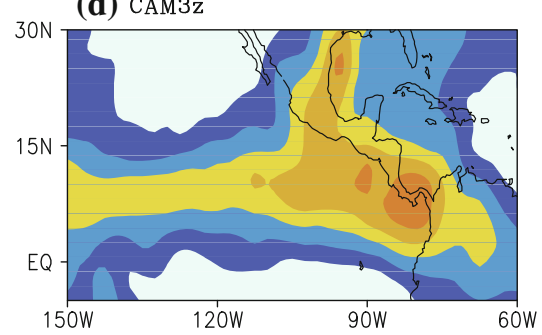

(f) CFS

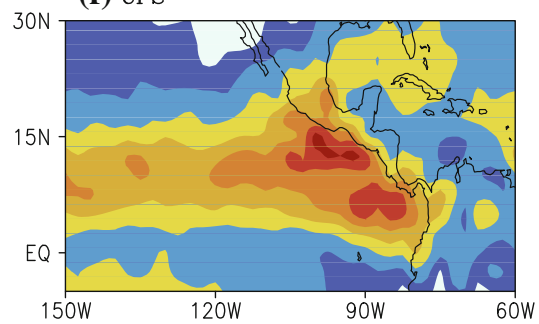

(h) $\mathrm{CM} 2.1$

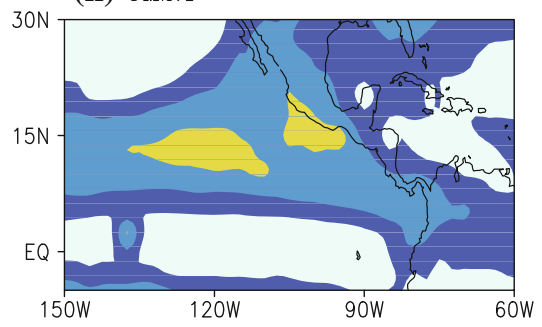

(j) HIRAM

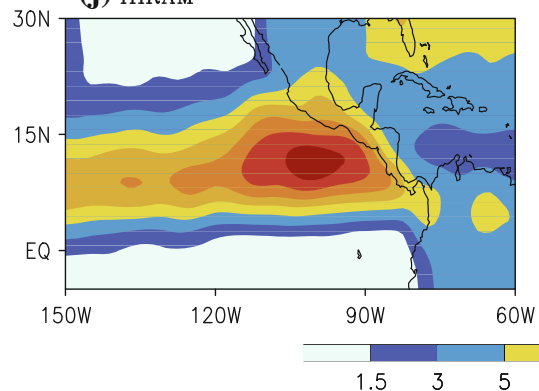

(c) ECHAM OPYC

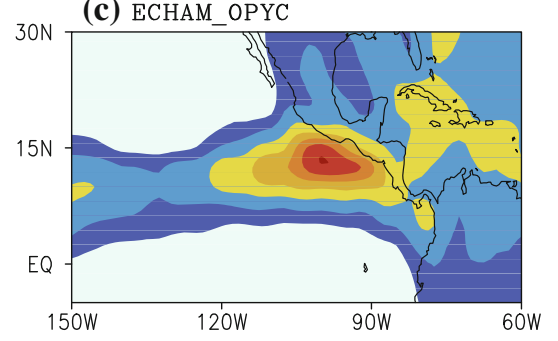

(e) GEOS5

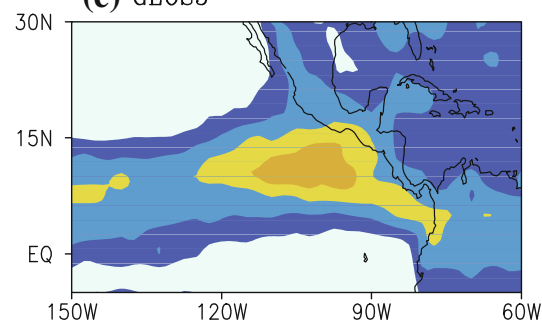

(g) $\mathrm{SNU}$

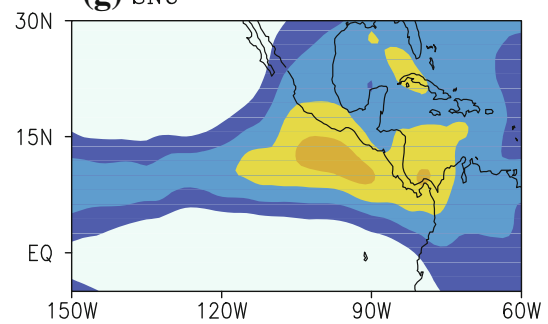

(i) SPCAM

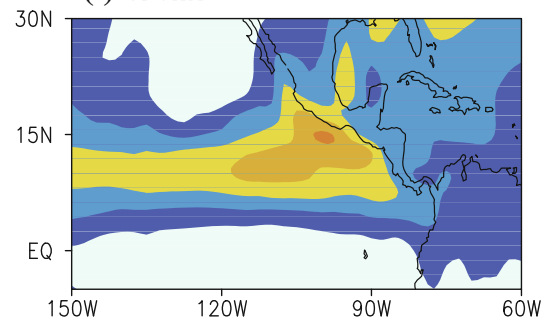

(k) HIRAM-lores

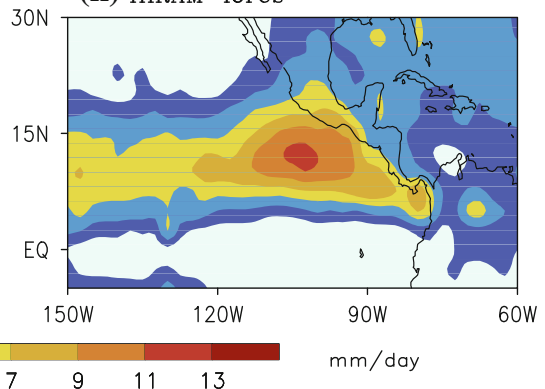


Fig. 3 (X-axis) Pattern correlation coefficients for summer mean (May-Oct) precipitation between TRMM observations and model simulations; (Y-axis) Relative domain-averaged amplitude of simulated summertime precipitation standard deviation in each model to its observational counterpart. Both pattern correlation of mean rainfall and domain-averaged amplitude of precipitation standard deviations are derived over the area of $5^{\circ} \mathrm{S}-30^{\circ} \mathrm{N}$, $150^{\circ} \mathrm{W}-80^{\circ} \mathrm{W}$. The star mark represents the observations
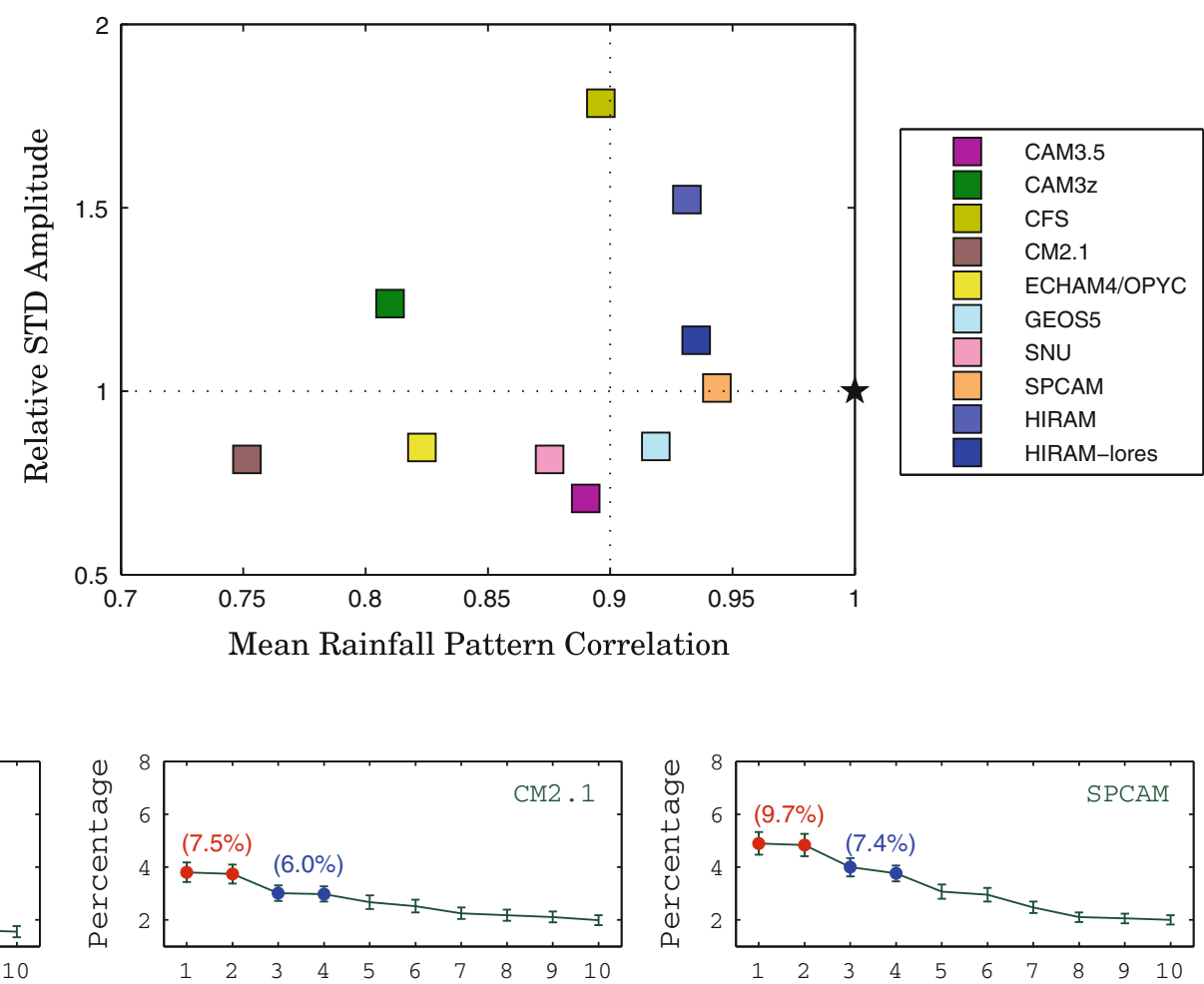

EEOF mode

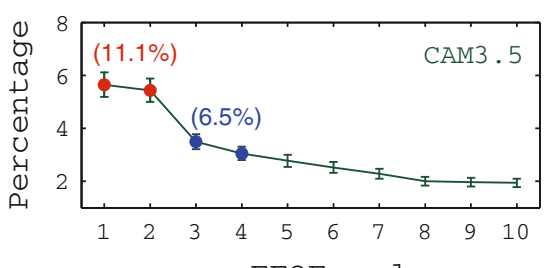

EEOF mode
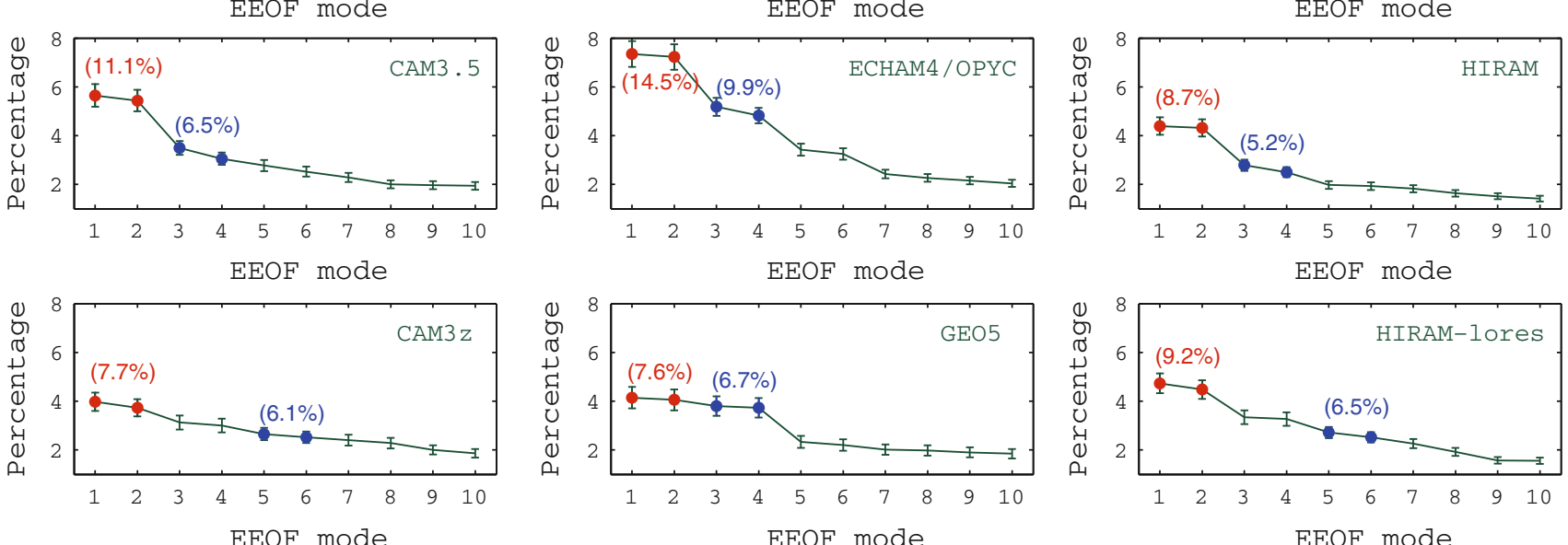

EEOF mode

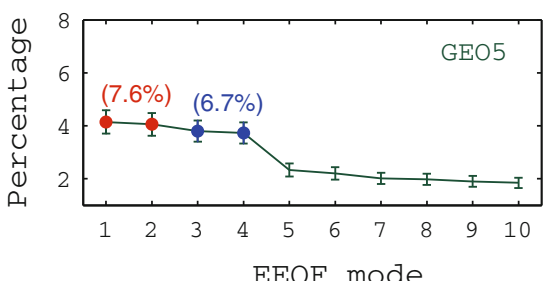

EEOF mode
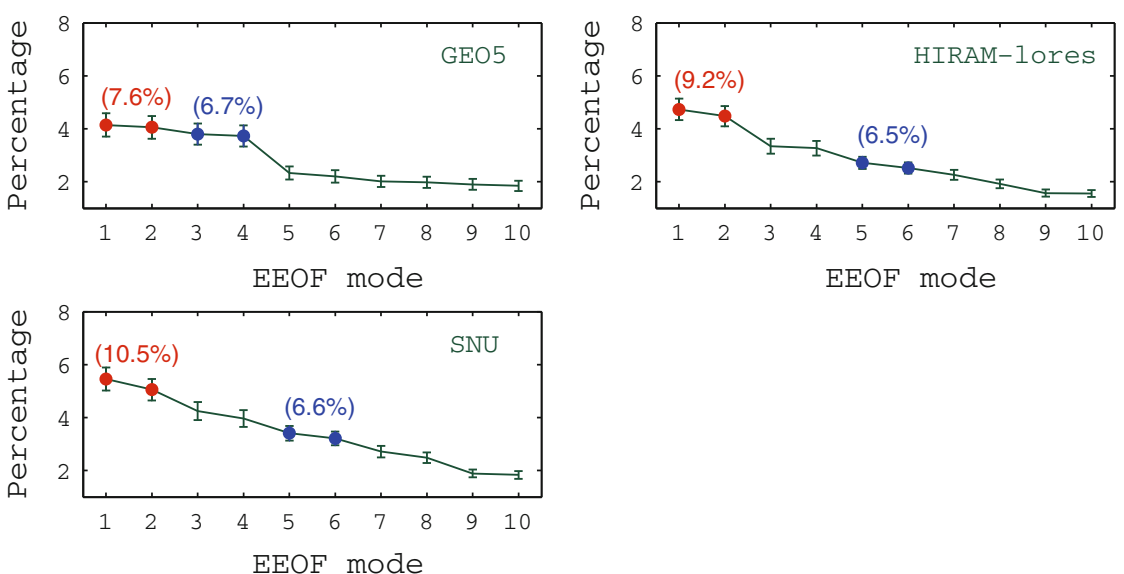

EEOF mode

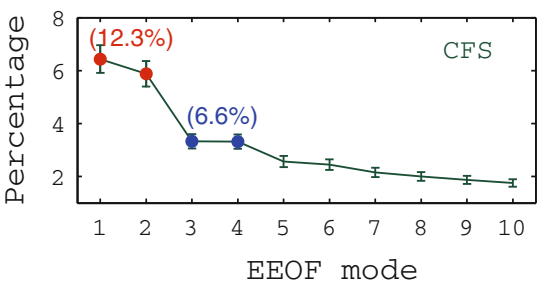

Fig. 4 Percentage variances explained by the first ten EEOF modes of summer (May-Oct) rainfall over the eastern Pacific $\left(140^{\circ} \mathrm{W}-\right.$ $90^{\circ} \mathrm{W}$; EQ- $30^{\circ} \mathrm{N}$ ) based on TRMM observations and model simulations. Error bars are determined based on the formula by North et al.

2-D evolution patterns. Then, the maximum absolute value of these lead/lag correlation coefficients is selected to represent the pattern correlation between each model EEOF mode and the observed $\mathrm{EEOF}_{1} / \mathrm{EEOF}_{3}$. The EEOF
(1982). Leading modes as denoted by two red (blue) dots represent the two quadratic EEOFs corresponding to the first (second) ISV modes in each dataset with percentage of variance explained by each mode labeled above or below

mode with largest pattern correlation coefficient against the observed $\mathrm{EEOF}_{1} / \mathrm{EEOF}_{3}$ will then be selected as the corresponding first/second ISV mode in each model. Note that as in the observations, each leading ISV mode in GCM 
simulations is also usually described by a pair of EEOF modes in quadrature with each other (see Fig. 4). Thus, based on the above pattern correlation approach, a pair of EEOFs can be identified as a candidate model counterpart of the first (40-day mode) and second (QBM) ISV modes in each GCM simulation. Adopting observed $\mathrm{EEOF}_{2} / \mathrm{EEOF}_{4}$ instead of $\mathrm{EEOF}_{1} / \mathrm{EEOF}_{3}$ as a reference when conducting pattern correlations will lead to similar results.

The first and second leading ISV modes identified in each model, corresponding to the observed 40-day mode and the QBM, are denoted by red and blue dots in Fig. 4, along with the percentages of variances labeled in corresponding colors. In all the GCMs, the first two EEOFs $\left(\mathrm{EEOF}_{1}\right.$ and $\left.\mathrm{EEOF}_{2}\right)$ show the largest pattern correlation coefficients against the observed 40-day mode. While the pattern of the observed QBM is best depicted by second pair of EEOFs $\left(\mathrm{EEOF}_{3}\right.$ and $\left.\mathrm{EEOF}_{4}\right)$ in most of the GCMs, it is captured in the third pair of EEOFs $\left(\mathrm{EEOF}_{5}\right.$ and $\mathrm{EEOF}_{6}$ ) in $\mathrm{CAM} 3 \mathrm{z}, \mathrm{SNU}$, and HIRAM-lores. The two pairs of EEOFs corresponding to the observed first and second ISV modes are in general well separated from each other in most of the GCMs except GEO5, in which an overlap of explained variances is evident between the first and second pairs of EEOF modes. It is worth mentioning, however, that not all these identified ISV modes in GCM simulations in Fig. 4 are able to realistically capture the observed two leading ISV modes over the EPAC.

The pattern correlation coefficients of the first and second modes between model simulations and observations are illustrated in Fig. 5. The results suggest that four GCMs, including CFS, SPCAM, HIRAM, and SNU, show the better skills in capturing the observed evolution pattern of the first ISV mode with pattern correlations surpassing 0.8 . Particularly noteworthy is that both the standard and low-resolution versions of HIRAM exhibit excellent skill in depicting the observed 40-day ISV mode. This result may suggest that model physics rather than the horizontal resolution may play a more essential role in faithfully simulating the 40-day mode over the EPAC. On the other hand, three GCMs, SPCAM, HIRAM, and GEOS5, demonstrate the best skill in simulating the second ISV mode, i.e., the QBM, with pattern correlations greater than 0.6. Caution needs to be exercised on the QBM in GEOS5 since this mode is not statistically significant based on North et al. (1982)'s criterion. It is interesting to note that while the QBM is well represented in the standard HIRAM, it is not well captured in its lower resolution version. This result suggests the importance of fine horizontal resolution in simulating the observed QBM over the EPAC, which may be due to the smaller scales of the QBM versus the 40-day ISV mode. Despite the coarse resolution (T42) of the parent GCM of SPCAM, the QBM is also well simulated by the SPCAM, indicating that an improved simulation of the convective processes by the embedded 2D CRMs could represent another method for improving simulations of the ISV over the EPAC.

Next, the dominant periodicities of the two leading ISV modes in each dataset are further examined by spectral analyses, which are applied to unfiltered principal components (PCs) corresponding to each ISV mode to mitigate possible effects caused by band-pass filtering. The unfiltered PCs are obtained by projecting the EEOFs corresponding to the leading ISV modes in each dataset onto unfiltered rainfall data (with the climatological annual cycle removed). The power spectrum of a particular ISV mode is then derived by averaging the spectra corresponding to the two quadratic EEOFs associated with this mode. Figure 6 illustrates the spectral density profiles of leading ISV modes based on both observed and model simulated rainfall, which have been normalized by their corresponding maximum values such that the peak value is unity in each profile. Spectral analysis based on TRMM rainfall (left columns in Fig. 6a, b) are consistent with JW09 and further confirm the dominant periods of about 40 and 16 days associated with the observed first and second leading ISV modes over the EPAC. For the first ISV mode (Fig. 6a), CFS captures a spectral peak of about 50 days, while CAM3z, SNU, SPCAM, and HIRAM_lores simulate dominant periods of about 35 days, reasonably comparable to the observations. Higher frequency spectral peaks of the first ISV mode are found in other GCMs. Also note that although a peak spectrum of about 25 days is noticed in the standard HIRAM run, a second peak of about 35 days can also be detected. Meanwhile, a second 25-day peak is also noticed in the HIRAM_lores run, suggesting coexistence of these two prevailing periods in HIRAM and a shifting

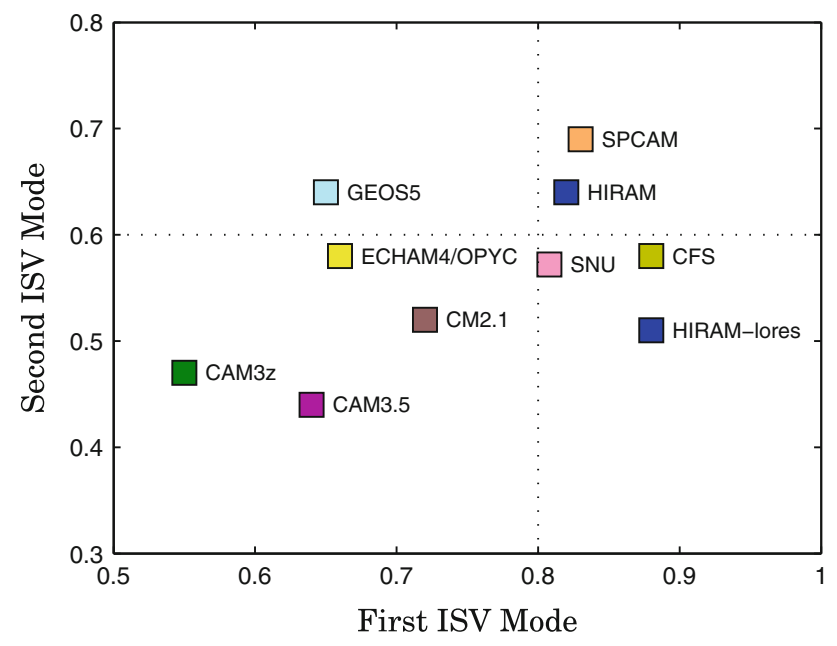

Fig. 5 Pattern correlation coefficients of the first ISV mode (x-axis)/ second ISV mode (y-axis) between TRMM observations and simulations 
between each other with the change of the model horizontal resolution.

For the dominant periods of the second ISV mode, most of GCMs, except CM2.1, ECHAM4/OPYC, and HIRAMlores, reasonably capture a quasi-biweekly period of the second ISV mode (Fig. 6b). In GEOS5, a higher-frequency mode with a period of 12 days is dominant, while a period of about 30 days is found in CM2.1 and HIRAM-lores, and about 50 days in ECHAM4/OPYC. It is of particular interest to note that while a biweekly period of the second ISV mode is realistically simulated in the standard HIRAM run, it is not captured in its lower resolution version. This result further suggests that the increased horizontal resolution could be conducive to a better representation of the QBM over the EPAC.

The evolution patterns of anomalous rainfall and $850 \mathrm{hPa}$ winds associated with the first ISV mode in the four aforementioned GCMs that exhibit better skill in pattern correlations are illustrated in Fig. 7 along with their observational counterpart. In accord with previous studies (e.g., Maloney and Esbensen 2007; Jiang and Waliser 2008), the observed 40-day ISV mode is largely characterized by an eastward propagation (Fig. 7a). Anomalous southwesterly (northeasterly) low-level winds are found to be associated with enhanced (suppressed) convection. These observed features are largely captured in these GCM simulations although model deficiencies are also readily discerned. Consistent with strong ISV in the CFS as shown in Fig. 2f, it has much stronger ISV amplitude over the EPAC during its life cycle (Fig. 7b). While the observed ISV signals are largely confined to the north of $5^{\circ} \mathrm{N}$, the signals are also apparent near the equator in the CFS simulation. For SNU (Fig. 7c), instead of a gradual eastward extension of the enhanced ISV convective signals as
Fig. 6 Normalized spectral density of unfiltered PC time series derived by projecting $\mathbf{a}$ the first ISV mode and $\mathbf{b}$ the second ISV mode onto unfiltered TRMM and model simulated rainfall anomalies (seasonal cycle removed) (a) First ISV Mode

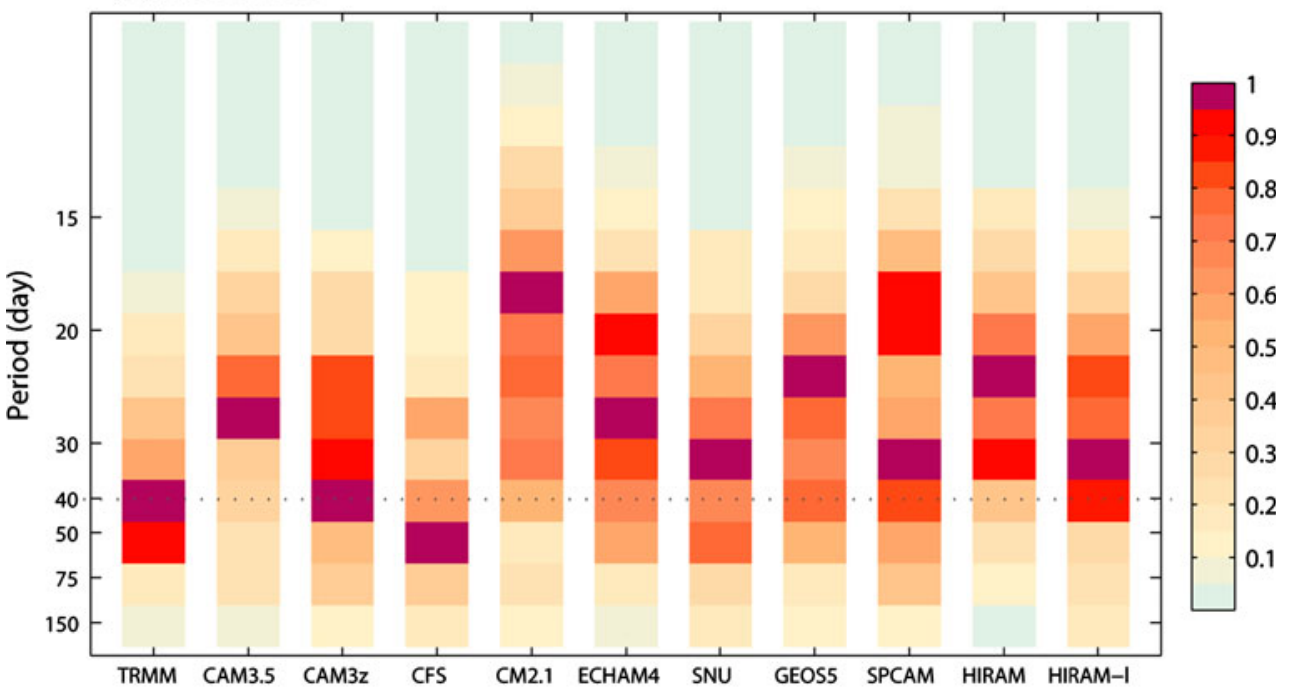

(b) Second ISV Mode

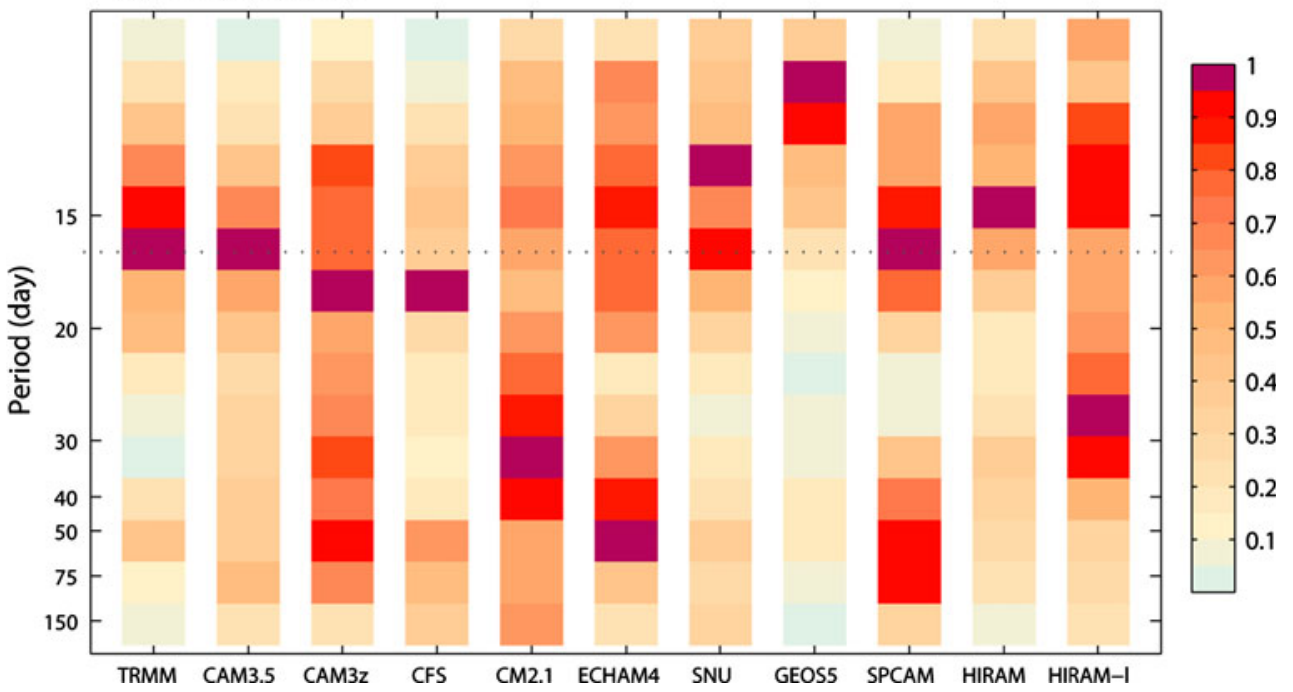


in the observations, the eastward shift of the ISV signals occurs very quickly from day -9 to day -6 ; then a quasistationary enhanced rain belt is evident along the EPAC ITCZ until day 0 . The ISV simulated in the two versions of GFDL HIRAM generally exhibit similar evolution features. The increased horizontal resolution in the standard HIRAM promotes the capture of local details of the observed ISV distribution and their evolution. For example, based on TRMM observations, the initiation of a suppressed convection signal first appears to the south of previously enhanced convection near $120^{\circ} \mathrm{W}$ (Fig. 7a, day 6). This process is well simulated in HIRAM (Fig. 7e, days 0-3) although there is a slight eastward shift of the observed counterpart, but not in its low-resolution version. It is also worthwhile to mention that this initiation process of the suppressed convection to the south of the previously enhanced convection is also detected in SPCAM (Fig. 7d, day 6), which may benefit from the embedded 2-D CRMs in spite of the relatively coarse horizontal resolution in its parent GCM of SPCAM.

In Fig. 8, the eastward propagation associated with the first ISV mode over the EPAC is further examined by displaying time-longitude profiles of rainfall anomalies based on both observations and GCM simulations. To explore a possible linkage between the ISV over the EPAC and the western Pacific (WPAC), the Hovmöller diagram based on each dataset in Fig. 8 covers longitudes ranging from $115^{\circ} \mathrm{E}$ to $80^{\circ} \mathrm{W}$. Considering that eastward propagating ISV signals are mainly confined near the equator over the western Pacific, while they are largely trapped along the off-equatorial ITCZ over the EPAC, the rainfall in each panel is averaged between $10^{\circ} \mathrm{S}$ and $15^{\circ} \mathrm{N}$ over the longitudes west of $150^{\circ} \mathrm{W}$, and between $5^{\circ} \mathrm{N}$ and $15^{\circ} \mathrm{N}$ east of $150^{\circ} \mathrm{W}$. The slope of the dashed line over the eastern sub-domain of each panel represents the observed eastward phase speed of $4^{\circ}$ day $^{-1}$ between $140^{\circ} \mathrm{W}$ and $100^{\circ} \mathrm{W}$ (Fig. 8a). To the east of $100^{\circ} \mathrm{W}$, the westward propagating signal of the 40-day ISV mode is also observed.

First the eastward propagation of the first ISV mode over the EPAC region (eastern sub-domains) in GCM simulations is examined. It is shown that the four GCMs that exhibit relatively higher pattern correlation coefficients for the 40-day mode, i.e., CFS, SNU, SPCAM, and HIRAM as shown in Fig. 5, generally simulate a more realistic eastward propagation of this mode over the EPAC. Both HIRAM versions capture well the eastward propagation of the first ISV mode. While the eastward propagation is reasonably well represented in SPCAM, the westward propagation near $100^{\circ} \mathrm{W}$ tends to be overestimated in this model. Consistent with our previous discussion, a very fast eastward propagation speed of about $15^{\circ}$ day $^{-1}$ over the EPAC is found in SNU. The eastward propagation over the EPAC associated with the 40-day ISV mode is not well defined in several other GCMs, including CAM3.5, ECHAM4/OPYC, CAM3Z, GEOS5, and CM2.1. Moreover, relatively higher frequencies of the simulated first ISV mode compared to the observations are also clearly discerned in most of the GCMs (except CFS) based on Fig. 8.

A noteworthy feature as illustrated by Fig. 8a is that the observed ISV signals over the EPAC are closely linked to the eastward propagating ISV over the WPAC, which can be further traced back to ISV signals over the Indian Ocean (not shown). This result may indicate the intimate linkage between the MJO and 40-day ISV mode over the EPAC, which is in agreement with a previous study by Maloney and Esbensen (2007) in which a very similar evolution pattern of the 40-day ISV mode as shown in Fig. 7a can be obtained by a lag-regression onto a global MJO index instead of a local ISV index in the present study. In this regard, the 40-day ISV mode over the EPAC is generally regarded as the local expression of the global MJO. This is in agreement with regional model results by Small et al. (2011), which suggest that the phase of the ISV over the EPAC is determined by remote forcing associated with the MJO. Nevertheless, this strong linkage of the eastward propagating MJO from the Indian Ocean/WPAC and the 40-day ISV over the EPAC is not evident in the GCM simulations. The convective signals associated with the 40-day ISV mode over the EPAC tend to originate over the central Pacific between $150^{\circ} \mathrm{E}$ and $150^{\circ} \mathrm{W}$ based on simulations by several GCMs that exhibit a more realistic 40-day ISV mode over the EPAC. While further investigation is needed for a better understanding of the model deficiencies, these results indicate that the 40-day ISV mode over the EPAC could be sustained without a forcing from the eastward propagating MJO.

In addition to the eastward propagation, recent study by Jiang and Waliser (2008) and Maloney et al. (2008) illustrated that this 40-day ISV mode over the EPAC also exhibits northward movement as has been similarly documented for the ISV associated with the Asian summer monsoon (e.g., Jiang et al. 2004; Annamalai and Sperber 2005). Moreover, similar to its counterpart over the Indian Ocean, this northward propagating ISV over the EPAC is also characterized by positive anomalies of equivalent barotropic vorticity, lower-tropospheric specific humidity, and PBL convergence to the north of the ISV convection center. All these features are consistent with the "easterly vertical wind shear" mechanism previously proposed to explain the northward propagation of the ISV (Jiang et al. 2004), as both the Asian monsoon region and the EPAC are characterized by the easterly vertical wind shear associated with the Asian and North American monsoons (Jiang and Waliser 2008). 
(a) TRMM $/ E R A-1$
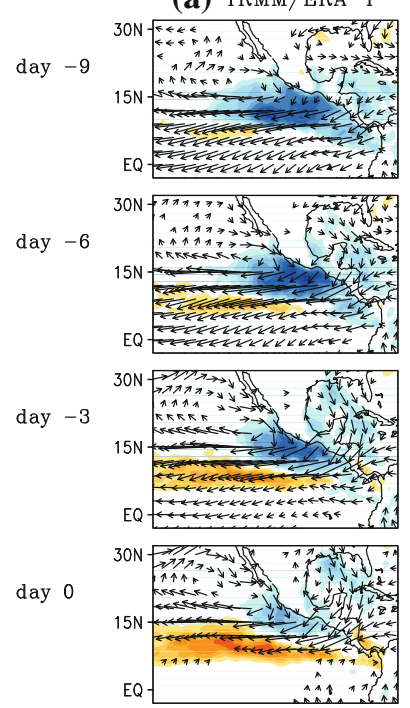

day 3

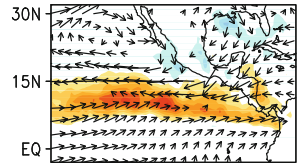

day 6

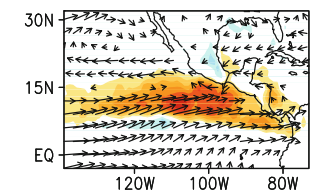

(b) $\mathrm{CFS}$
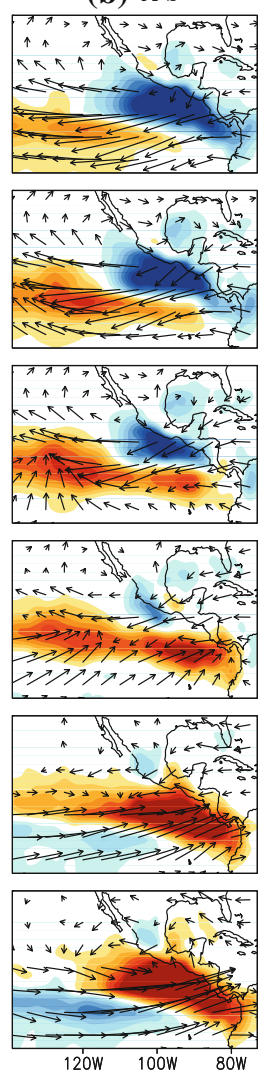

(c) $\mathrm{SNU}$
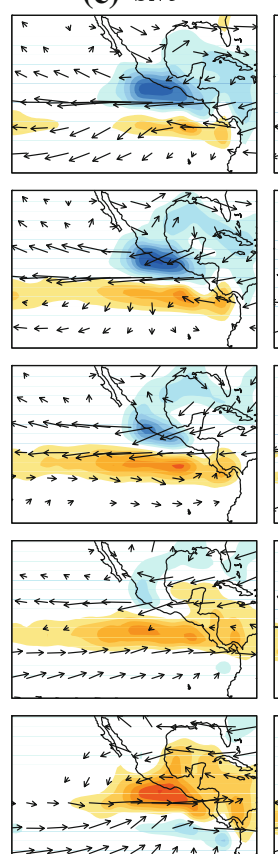

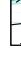

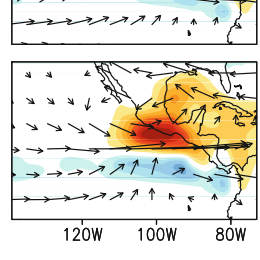

(d) SPCAM
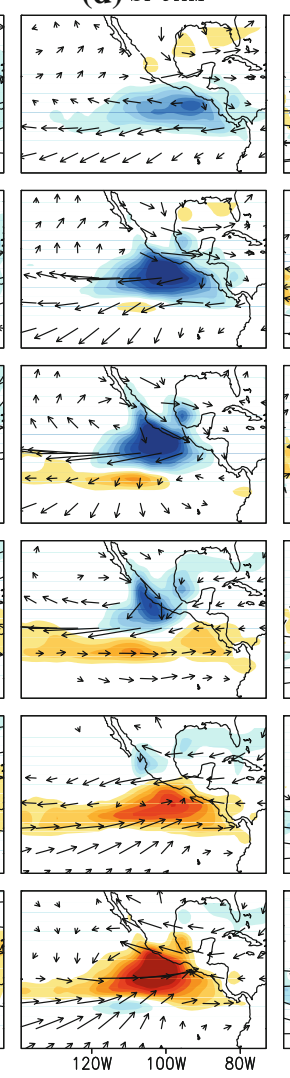

(e) HIRAM

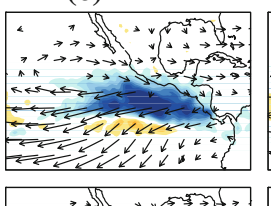

(f) HIRAM-lores
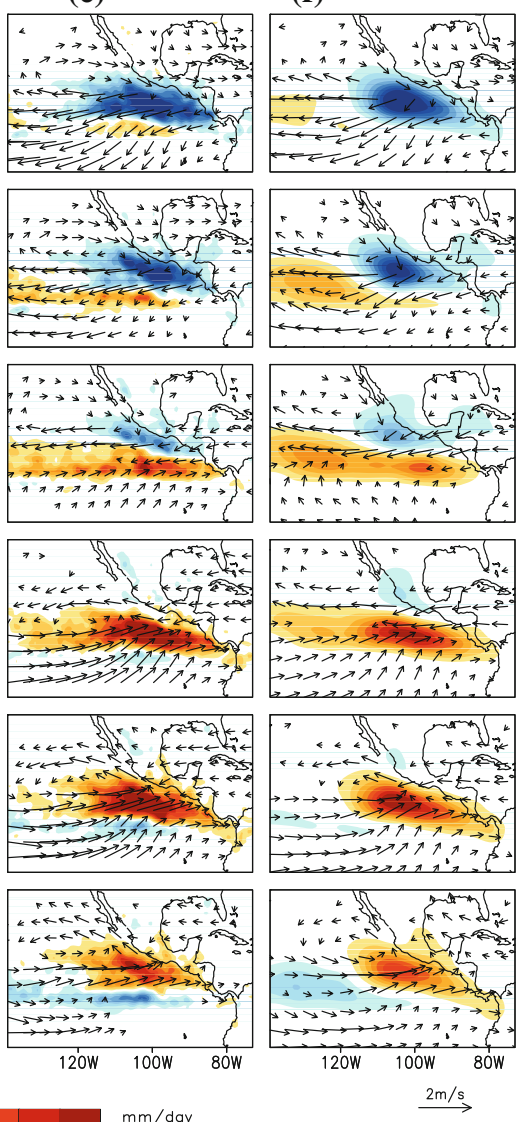

Fig. 7 Evolution of anomalous rainfall (shaded) and $850 \mathrm{hPa}$ winds (vectors) of the first ISV mode over the EPAC based on observations (a) and GCM simulations (b-f), which was derived by lag-regression of these fields versus the PC time series of the $\mathrm{EEOF}_{1}$ (the EEOF with the largest pattern correlation with the observed $\mathrm{EEOF}_{1}$ ) based on rainfall in observations (GCM simulations). Wind vectors smaller than $0.15 \mathrm{~m} \mathrm{~s}^{-1}$ are omitted

winds associated with the second ISV mode based on three GCMs (SPCAM, HIRAM, and GEOS5) which exhibit relatively higher pattern correlation scores for this mode as presented in Fig. 5. In the observations (Fig. 10a), the second ISV mode (QBM) over the EPAC is largely characterized by a northward propagating dipole pattern with a spatial scale smaller than the 40-day ISV mode shown in Fig. 7a. The three GCMs reasonably capture the bulk evolution features of the QBM, although the model simulated QBM patterns tend to exhibit a stronger westward propagation component in addition to the northward movement.

The northward propagation of rainfall anomalies associated with the second ISV mode in both observations and GCMs is further displayed in Fig. 11, where the dashed lines denote the observed northward phase speed of about $1.2^{\circ}$ day $^{-1}$. In addition to the aforementioned three GCMs in Fig. 10, ECHAM4/OPYC, SNU, CAM3z, and CFS also capture reasonably well the northward propagation signals. 

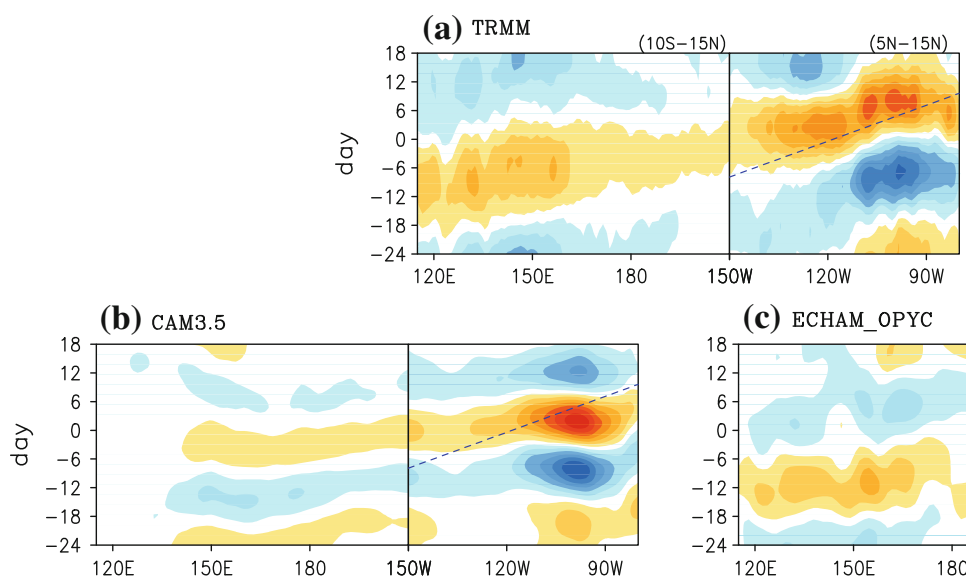

(c) ECHAM_OPYC
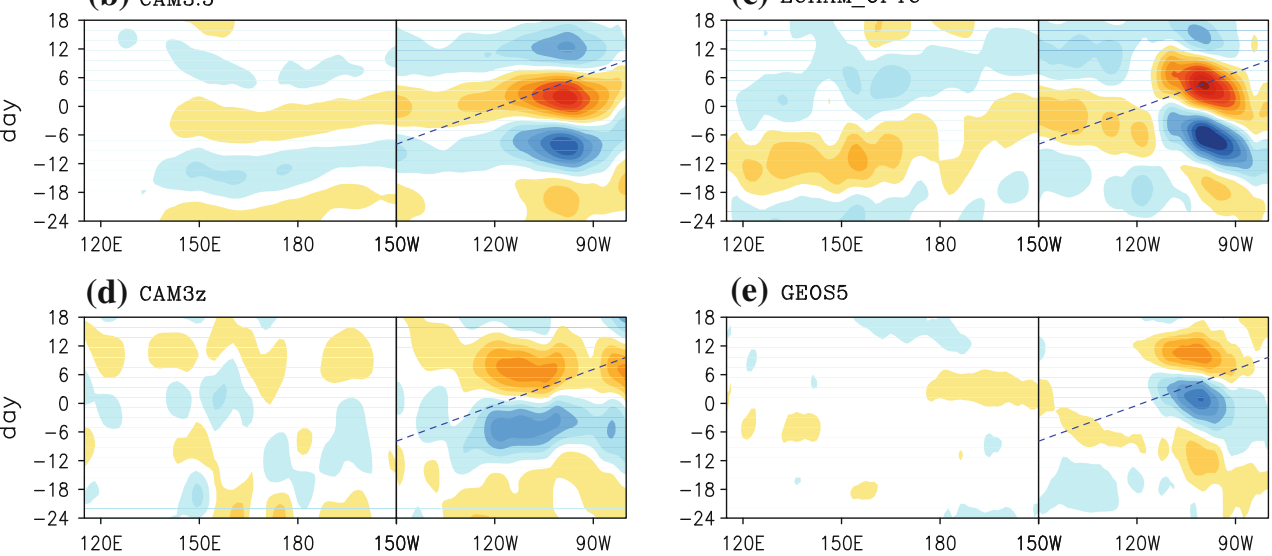

(e) GEOS5
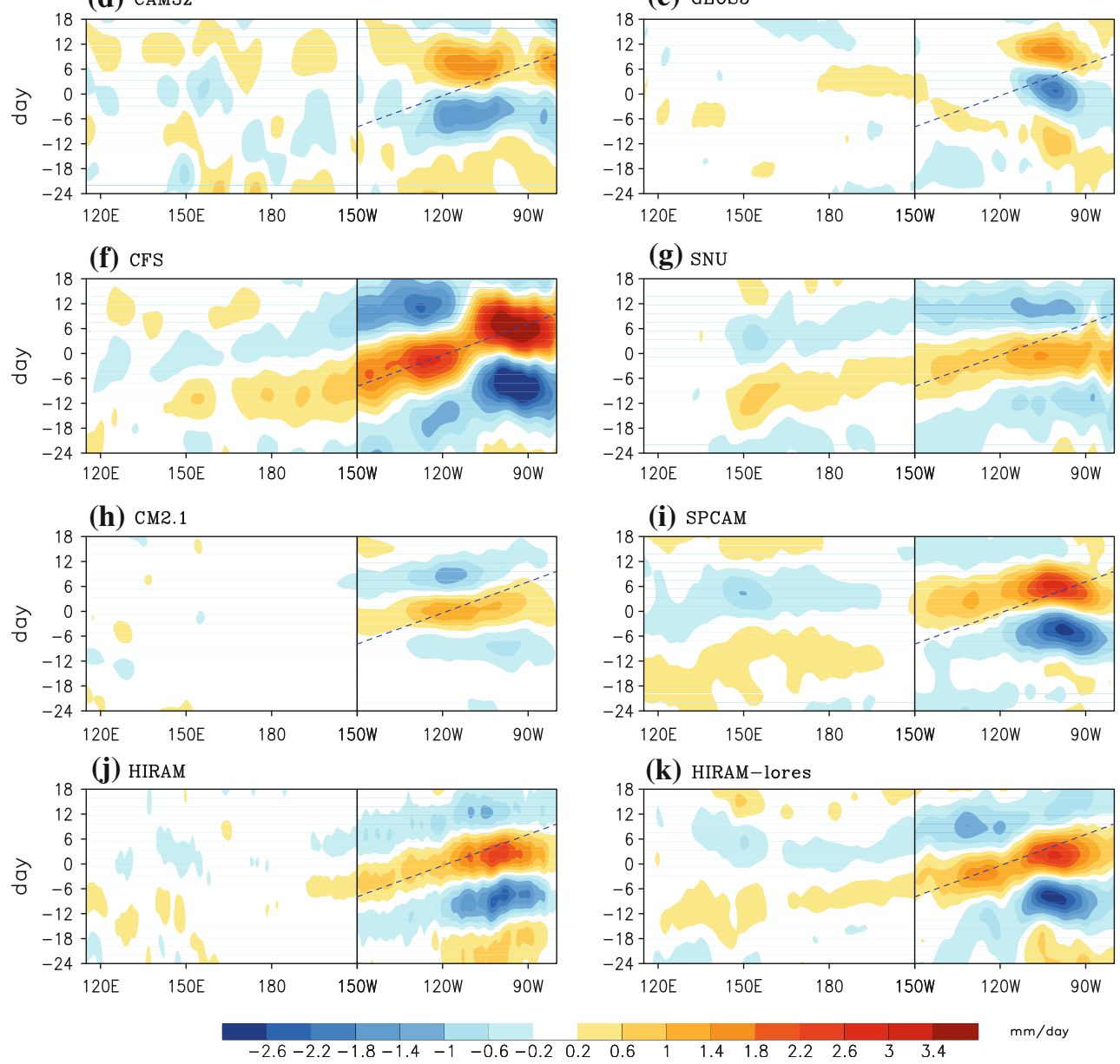

Fig. 8 Longitude-time evolution of rainfall anomalies associated with the first ISV mode based on observed and GCM simulated rainfall. The rainfall in each panel is averaged between $10^{\circ} \mathrm{S}$ and

The northward propagation is largely absent in CAM3.5, CM2.1, and HIRAM-lores. It is worthwhile to mention again that although the northward propagation of the QBM is very well captured by the HIRAM standard resolution run, it fails to be captured in its low-resolution run. $15^{\circ} \mathrm{N}$ over the longitudes west of $150^{\circ} \mathrm{W}$, and between $5^{\circ} \mathrm{N}$ and $15^{\circ} \mathrm{N}$ east of $150^{\circ} \mathrm{W}$. Dashed line over the eastern sub-domain in each panel represents an eastward propagation phase speed of $4^{\circ}$ day $^{-1}$

\section{Summary and discussion}

During boreal summer, convective activity over the EPAC is characterized by vigorous intraseasonal variability, which exerts a significant influence on regional climate and 
(a) TRMM

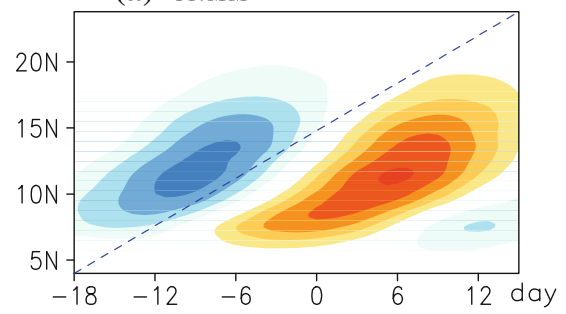

(b) CAM3.5

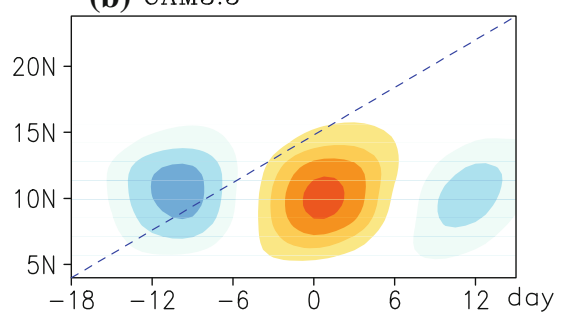

(d) CAM3z

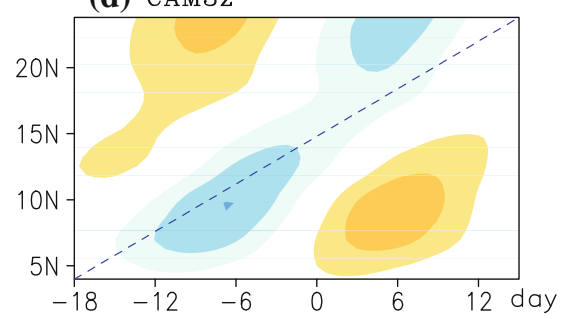

(f) $\mathrm{CFS}$

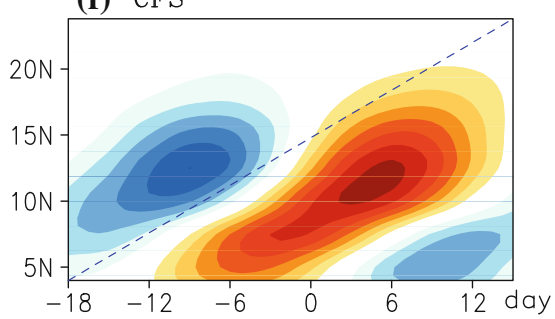

(h) CM2.1

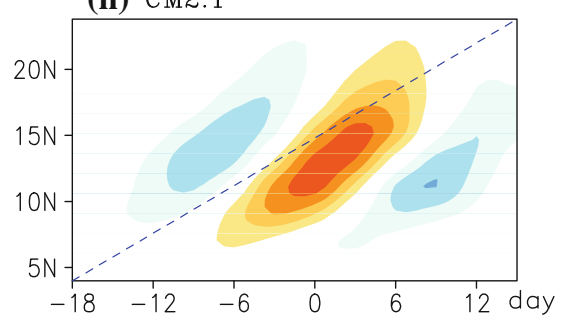

(j) HIRAM

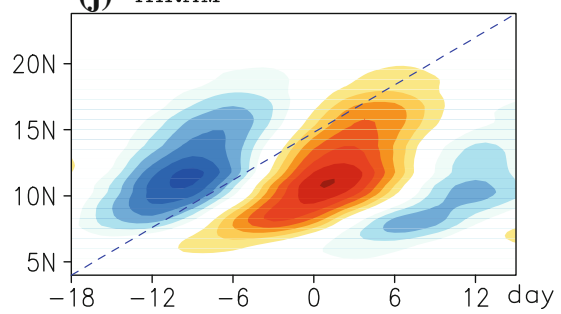

(c) ECHAM_OPYC

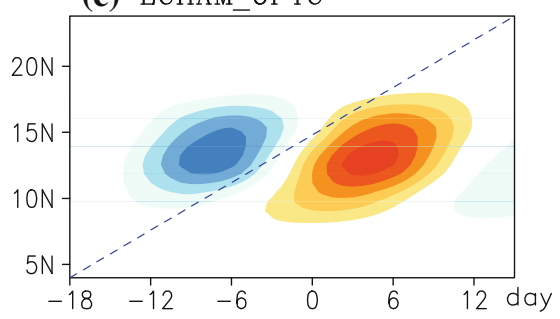

(e) GEOS5

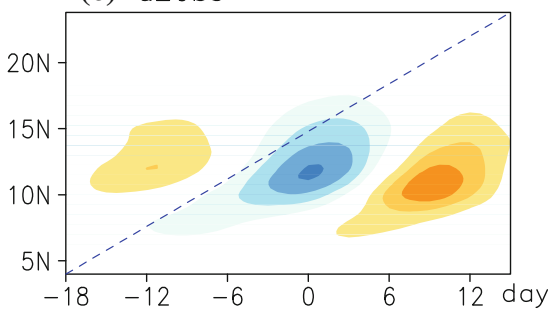

(g) $\mathrm{SNU}$

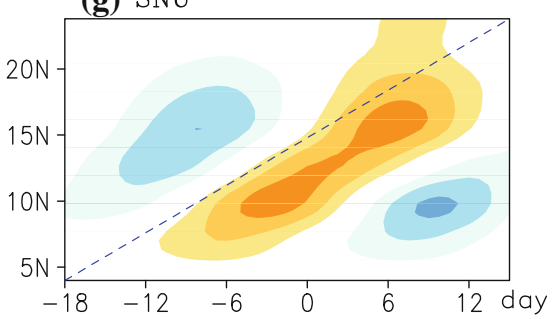

(i) SPCAM

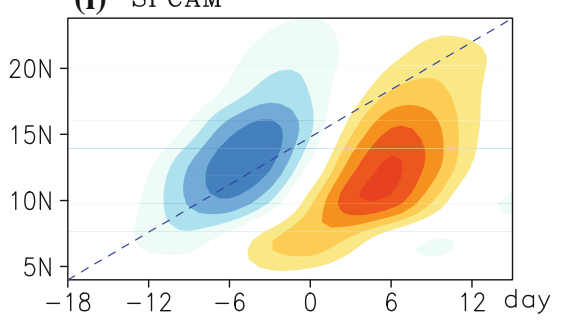

(k) HIRAM-lores

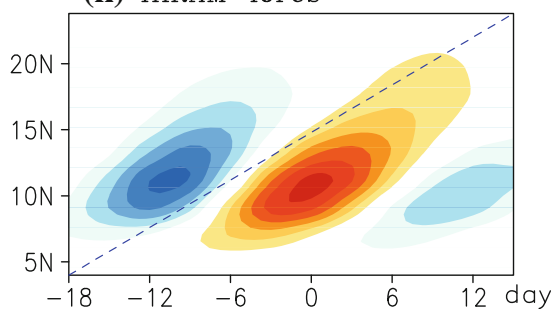

Fig. 9 Latitude-time evolution of rainfall over the EPAC $\left(130^{\circ} \mathrm{W}-90^{\circ} \mathrm{W}\right)$ of the first ISV mode based on TRMM observations and GCM simulations. Dashed lines represent a northward propagation speed of $0.6^{\circ}$ day $^{-1}$ 
(a) TRMM /ERA-I

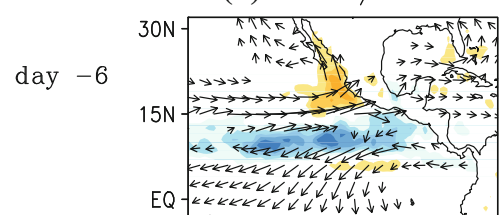

day -3
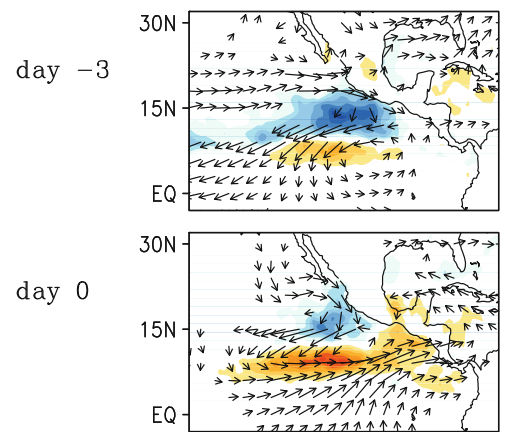

day 3

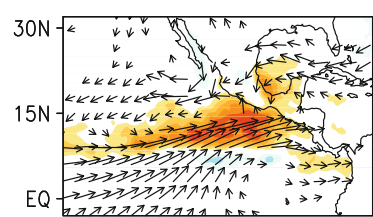

day 6

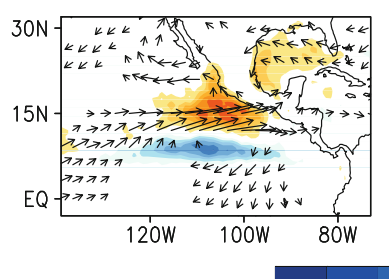

(b) GEOS5
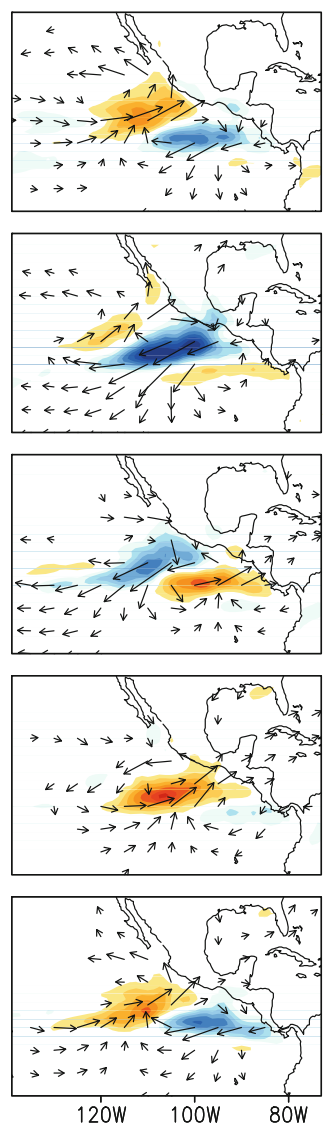

(c) SPCAM
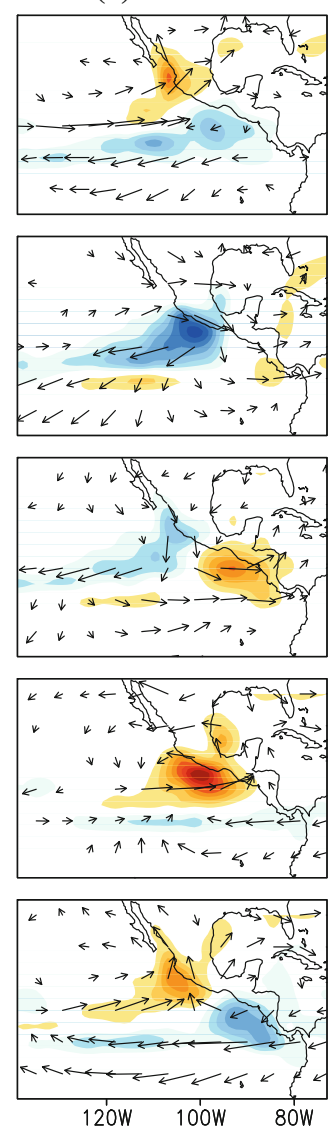

(d) HIRAM $2 \mathrm{~m} / \mathrm{s}$
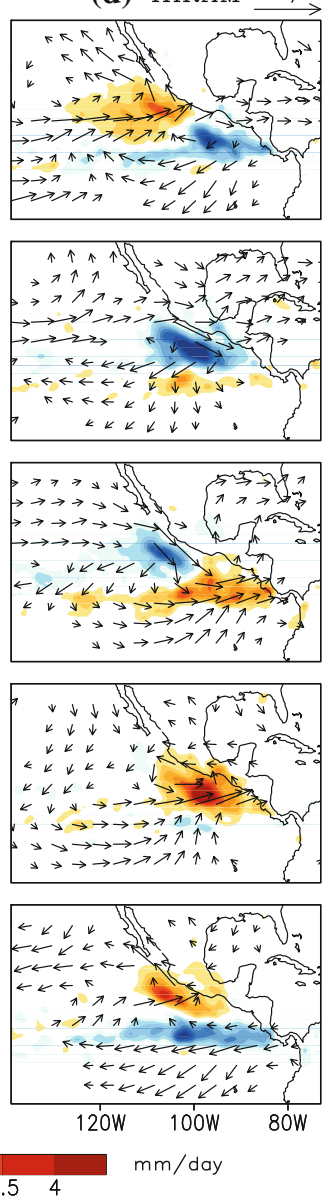

Fig. 10 Similar as in Fig. 7, but for evolution of rainfall (shaded) and $850 \mathrm{hPa}$ winds (vectors) associated with the second ISV mode over the EPAC based on observations and GCM simulations

extreme weather events. Therefore, improved understanding of, and increased predictive skill, for the ISV over the EPAC is of great importance to the extended-range regional climate prediction. Moreover, while current model capabilities in simulating the ISV over the eastern hemisphere have been extensively explored, particularly that over the Indian Ocean and western Pacific warm pool region, investigation of model fidelity in representing the ISV over the EPAC ITCZ remains limited.

In the present study, we assess capabilities of current GCMs in simulating the ISV over the EPAC by analyzing simulations from six atmospheric-only and three coupled GCMs. These models include the super-parameterized SPCAM AGCM, the NOAA operational CFS forecast model, and the newly developed high resolution HIRAM AGCM from GFDL. The results presented in this study, thus, represent recent advances in modeling the ISV. Model output from a low resolution version of HIRAM is also analyzed to explore the sensitivity to horizontal resolution on simulation of the ISV over the EPAC. We focus our diagnosis on the two dominant ISV modes over the
EPAC that have been recently identified based on TRMM rainfall observations, namely, a 40-day mode and a QBM. The periodicities, evolution patterns, and propagation features associated with these two ISV modes based on model simulations are compared to their observed counterparts.

While it remains a great challenge for GCMs to faithfully represent the two leading ISV modes over the EPAC, a number of models exhibit encouraging simulations of many of the key features of these ISV modes. For the first ISV mode, i.e., the 40-day mode, four GCMs, CFS, SNU, SPCAM, and HIRAM, display relatively better skill in simulating the evolution pattern associated with this ISV mode including the eastward and northward propagation. Except for the CFS, which captures a 50-day spectral peak of the first ISV mode, the first ISV mode simulated in the other three aforementioned GCMs exhibits a higher frequency than the observed 40-day period. Moreover, CFS suffers from a too active ISV over the EPAC. ISV signals simulated in the CFS can be discerned near the equator over the EPAC where the ISV is greatly damped in observations. Slightly stronger ISV amplitude is also found 
Fig. 11 Same as Fig. 9, but for the second ISV mode. The dashed line in each panel denotes the northward propagation phase speed of $1.2^{\circ}$ day $^{-1}$ for the observed QBM over the EPAC

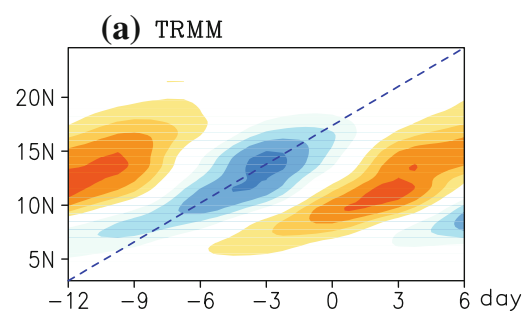

(b) CAM3.5

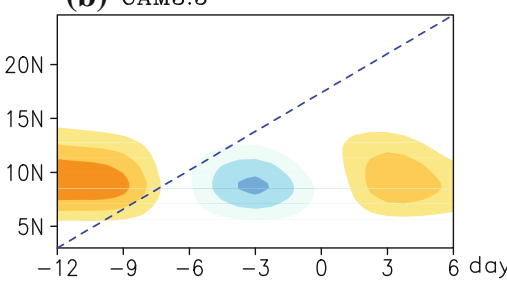

(c) ECHAM_OPYC

(d) CAM3z
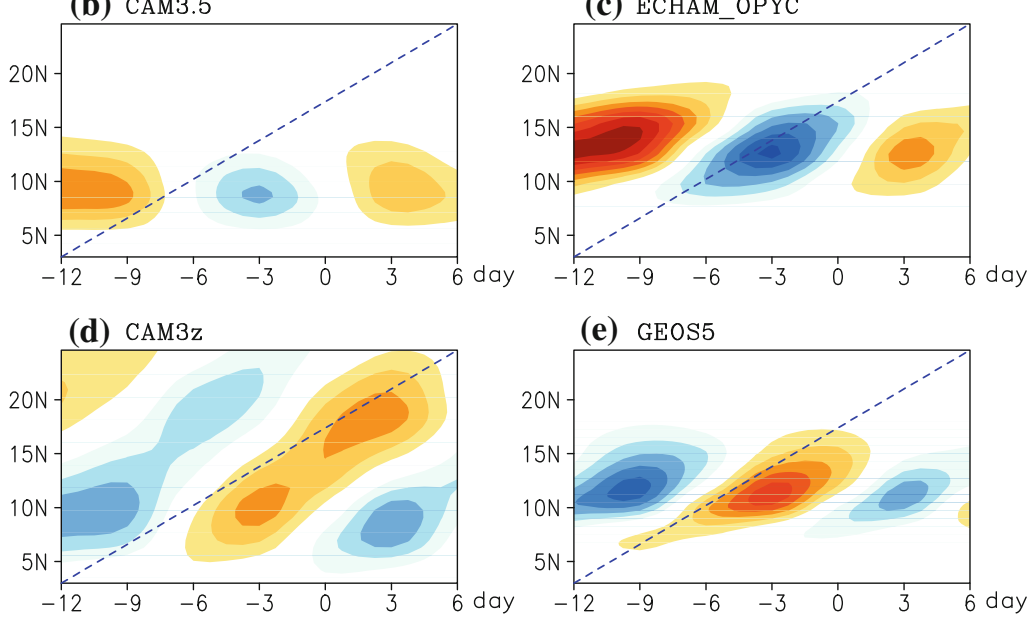

(e) GEOS5

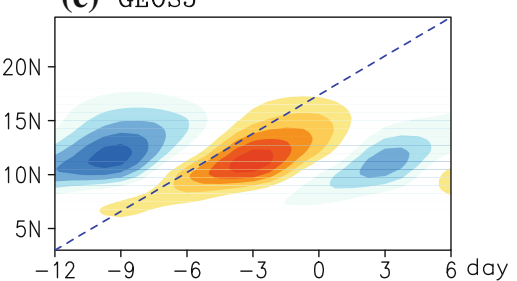

$\mathrm{mm} /$ day

3.5

3

2.5

2

0.5

$-0.5$

$-1$

$-1.5$

$-2$

$-2.5$

(h) CM2.1
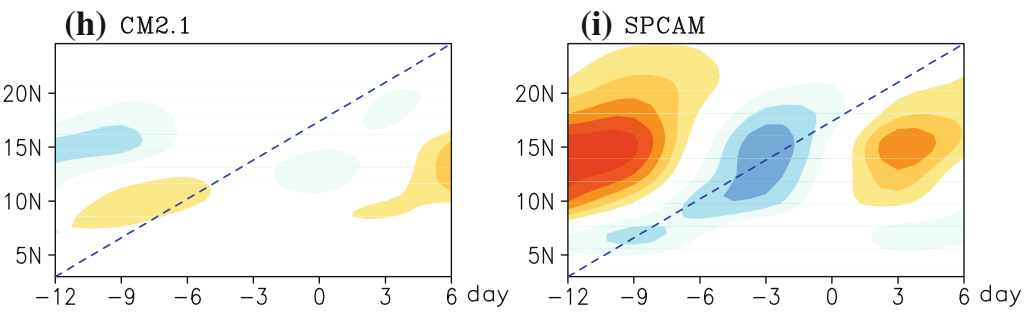

$-3$

$-3.5$

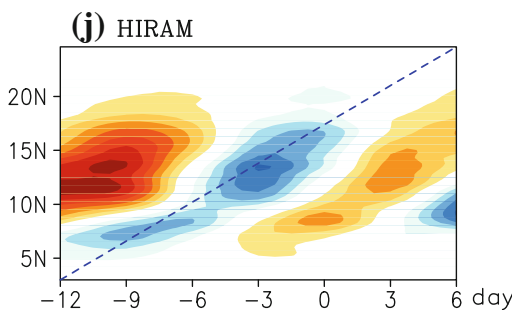

(k) HIRAM-lores

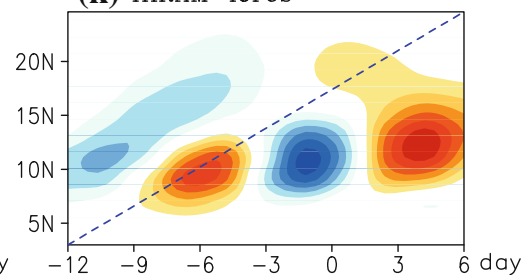

in HIRAM. It is noteworthy that both standard and low resolution versions of HIRAM capture the bulk features of the observed evolution patterns associated with the 40-day ISV mode, suggesting that improved model physics rather than the model horizontal resolution are essential for the improved simulation of the 40-day ISV mode in HIRAM over the GFDL CM2/AM2 on which HIRAM is based.

On the other hand, the quasi-biweekly period of the second ISV mode is captured by most of the GCMs with GEOS5, SPCAM, and HIRAM exhibiting the best skill in 
depicting the evolution of the observed QBM. It is noteworthy that while the standard HIRAM with a $50 \mathrm{~km}$ horizontal resolution captures well the general characteristics of the observed QBM, the low resolution version with a horizontal resolution of $250 \mathrm{~km}$ does not. This result indicates that fine horizontal resolution could be critical for capturing the second ISV mode over the EPAC, which could be partially due to the relatively smaller spatial scale features of the QBM.

Overall, SPCAM and HIRAM show relatively superior skill in depicting both of the two dominant ISV modes, as well the summer mean rainfall pattern over the EPAC. It is generally considered that the explicit representation of the sub-grid cumulus process by the embedded 2-D CRMs in SPCAM could be largely responsible for its improved performance. Similarly, the improved simulations of the ISV over the EPAC achieved in HIRAM over GFDL CM2/ AM2 could be largely ascribed to the improved cumulus parameterization schemes, most likely by adopting a strongly entraining plume cumulus scheme instead of the relaxed Arakawa-Schubert convective closure in AM2.1. It is largely believed that the adequate representation of rainfall from large-scale condensation in the GCMs could be essential to realistically simulate the life cycle of ISV convection processes (e.g., Fu and Wang 2009; Kim et al. 2009; Seo and Wang 2010). By adopting a strongly entraining cumulus scheme in HIRAM, the plume can only provide deep convection when the atmosphere is sufficiently moist. As a result, deep convection is sufficiently inhibited such that a substantial fraction of the rainfall in the tropics (30-40\% in both HIRAM and HIRAM_lores runs) occurs through the large-scale cloud module rather than through the convection module in HIRAM (Zhao et al. 2009). In contrast, only $7.5 \%$ of the total rainfall is through the large-scale condensation in AM2.1 (Zhao et al. 2009).

The improved skill for the ISV over the EPAC by adopting a strongly entraining cumulus scheme in HIRAM is consistent with modeling studies by applying a "Tokioka modification" on convective triggering following Tokioka et al. (1988). With the Tokioka modification, any convective plume with an entrainment rate less than a threshold value $\left(\mu_{\min }=\alpha / \mathrm{D}\right.$, here $\alpha$ is a constant parameter, and $\mathrm{D}$ is the PBL depth) will be suppressed. The constant $\alpha$ determines the strength of the triggering of convection. In other words, convection is less likely to occur when a larger $\alpha$ is applied. It has been shown that the simulation of the MJO is very sensitive to this parameter $\alpha$ (e.g., Lee et al. 2003; Lin et al. 2008a; Kim et al. 2011). The Tokioka modification is implemented in three GCMs analyzed herein, e.g., SNU, GEOS5, and CM2.1, with values of $\alpha$ of, 0.1, 0.05, and 0.025 , respectively. Therefore, relatively better skill in simulating the ISV over the EPAC in SNU model, in particular for the 40-day mode, could also benefit from the stronger Tokioka controls on convective triggering in this model. By either adopting a stronger entrainment rate as in HIRAM or applying a Tokioka modification in other GCMs, it makes convection more sensitive to environmental properties such as specific humidity. A strong sensitivity of convection on environmental moisture was also reported in SPCAM (Thayer-Calder and Randall 2009), consistent with superior skills in representing the ISV in this model. Moreover, as previously mentioned, an increase of the horizontal resolution appears to further help the simulation of the ISV over the EPAC, particularly for the second ISV mode.

It is shown that the observed 40-day ISV mode over the EPAC is closely linked to the eastward propagating ISV signals from the Indian Ocean/WPAC, which is largely consistent with previous regional model results that the phase of the ISV over the EPAC is determined by remote forcing associated with the MJO (Small et al. 2011). In contrast, in most of the GCMs with relatively more realistic simulation of the 40-day ISV mode over the EPAC, the convective signals associated with the 40-day mode over the EPAC tend to originate over the central Pacific between $150^{\circ} \mathrm{E}$ and $150^{\circ} \mathrm{W}$. These results suggest that the 40 -day ISV mode over the EPAC could be sustained without the forcing by the eastward propagating MJO. Along these lines, a more detailed analysis of the observations is called for to illustrate and quantify how often ISV events in the EPAC derive from eastward propagating events from the west versus those which develop locally.

It is also noteworthy that in the present study the dominant ISV modes in both observations and GCM simulations are identified based on EEOF analyses of 10- to 90-day filtered rainfall anomalies over the EPAC (EQ$\left.30^{\circ} \mathrm{N} ; 140^{\circ} \mathrm{W}-90^{\circ} \mathrm{W}\right)$. By conducting a similar EEOF analysis but for 10- to 20-day filtered outgoing long-wave radiation (OLR) over a greater domain including both the EPAC and Caribbean Sea (EQ- $30^{\circ} \mathrm{N} ; 130^{\circ} \mathrm{W}-60^{\circ} \mathrm{W}$ ), a recent study by Wen et al. (2011) suggested a second QBM over the eastern Pacific in addition to the largely northward propagating QBM as discussed in this study. This second QBM tends to be associated with westward propagating convective signals originated over the eastern Atlantic Ocean, which was also noted by Kikuchi and Wang (2009), and could be associated with the North American Monsoon variability on quasi-biweekly time scales (e.g., Jiang and Lau 2008; Wu et al. 2009).

The characteristics of the ISV over the EPAC share a number of common features with its counterpart over the south Asian monsoon region, including the two dominant intraseasonal oscillation periods, the coupling of northward and eastward propagation of the 40-day ISV mode, and the background easterly vertical wind shear associated with the 
monsoonal circulation. Thus, examination of the ISV over the EPAC will not only improve our understanding of the climate variability over the EPAC, but also provides independent and new perspectives on the mechanisms for the ISV. Further investigations are warranted for improved understanding on various aspects of the ISV over the EPAC, including the role of the MJO on the ISV over the EPAC, how the low- and high-frequency ISV modes interact to make impacts on regional climate/weather events, and the role of multi-scale interaction associated with the ISV over the EPAC.

Acknowledgments We thank anonymous reviewers for their critical comments on an earlier version of this manuscript. Thanks also to Terry Kubar for his comments and editorial assistance. The first author (XJ) acknowledges support by NOAA CPPA program under Award NA09OAR4310191 and NSF Climate and Large-Scale Dynamics under Award ATM-0934285. K. Sperber was supported under the auspices of the US Department of Energy Office of Science, Regional and Global Climate Modeling Program by Lawrence Livermore National Laboratory under contract DE-AC52-07NA27344. DK was supported by NASA grant NNX09AK34G. We thank U.S. CLIVAR MJO Working Group for coordinating this model comparison activity and modeling centers for providing the model output. Part of this research was carried out at the Jet Propulsion Laboratory, California Institute of Technology, under a contract with the National Aeronautics and Space Administration.

\section{References}

Aiyyer A, Molinari J (2008) MJO and tropical cyclogenesis in the Gulf of Mexico and Eastern Pacific: case study and idealized numerical modeling. J Atmos Sci 65:2691-2704

Anderson JL, Balaji V, Broccoli AJ, Cooke WF, Delworth TL, Dixon KW, Donner LJ, Dunne KA, Freidenreich SM, Garner ST, Gudgel RG, Gordon CT, Held IM, Hemler RS, Horowitz LW, Klein SA, Knutson TR, Kushner PJ, Langenhost AR, Lau NC, Liang Z, Malyshev SL, Milly PCD, Nath MJ, Ploshay JJ, Ramaswamy V, Schwarzkopf MD, Shevliakova E, Sirutis JJ, Soden BJ, Stern WF, Thompson LA, Wilson RJ, Wittenberg AT, Wyman BL, Dev GGAM (2004) The new GFDL global atmosphere and land model AM2-LM2: Evaluation with prescribed SST simulations. J Clim 17:4641-4673

Annamalai H, Sperber KR (2005) Regional heat sources and the active and break phases of boreal summer intraseasonal (30-50 day) variability. J Atmos Sci 62:2726-2748

Barrett BS, Leslie LM (2009) Links between tropical cyclone activity and Madden-Julian Oscillation Phase in the North Atlantic and Northeast Pacific Basins. Mon Weather Rev 137:727-744

Bosilovich MG, Schubert SD, Rienecker MM, Todling R, Suarez MJ, Bacmeister J, Gelaro R, Kim G-K, Stajner I, Chen J (2006) NASA's modern era retrospective-analysis for research and applications. US CLIVAR Var 4:5-8

Bretherton CS, McCaa JR, Grenier H (2004) A new parameterization for shallow cumulus convection and its application to marine subtropical cloud-topped boundary layers. Part I: description and 1D results. Mon Weather Rev 132:864-882

Chen TC, Chen JM (1993) The 10-20-Day Mode of the 1979 Indian Monsoon-its relation with the time-variation of monsoon rainfall. Mon Weather Rev 121:2465-2482 de Szoeke SP, Bretherton CS (2005) Variability in the southerly flow into the eastern Pacific ITCZ. J Atmos Sci 62:4400-4411

Delworth TL et al (2006) GFDL's CM2 global coupled climate models. Part I: formulation and simulation characteristics. J Clim 19:643-674

Fu X, Wang B (2009), Critical roles of the stratiform rainfall in sustaining the Madden-Julian oscillation: GCM experiments. J Clim 22:3939-3959

Fukutomi Y, Yasunari T (1999) 10-25 day intraseasonal variations of convection and circulation over East Asia and western North Pacific during early summer. J Meteorol Soc Jpn 77:753-769

Higgins RW, Shi W (2001) Intercomparison of the principal modes of interannual and intraseasonal variability of the North American Monsoon system. J Clim 14:403-417

Hong SY, Pan HL (1998) Convective trigger function for a mass-flux cumulus parameterization scheme. Mon Weather Rev 126:2599-2620

Huffman GJ, Adler RF, Rudolf B, Schneider U, Keehn PR (1995) Global precipitation estimates based on a technique for combining satellite-based estimates, rain-gauge analysis, and Nwp model precipitation information. J Clim 8:1284-1295

Janicot S, Sultan B (2001) Intra-seasonal modulation of convection in the West African monsoon. Geophys Res Lett 28:523-526

Jiang X, Lau N-C (2008) Intraseasonal teleconnection between North American and western North Pacific monsoons with 20-day time scale. J Clim 21:2664-2679

Jiang X, Waliser DE (2008) Northward propagation of the subseasonal variability over the eastern Pacific warm pool. Geophys Res Lett 35:L09814. doi:10.1029/2008GL033723

Jiang X, Waliser DE (2009) Two dominant subseasonal variability modes of the eastern Pacific ITCZ. Geophys Res Lett 36:L04704. doi:10.1029/2008GL036820

Jiang X, Li T, Wang B (2004) Structures and mechanisms of the northward propagating boreal summer intraseasonal oscillation. J Clim 17:1022-1039

Jiang X, Waliser DE, Wheeler MC, Jones C, Lee MN, Schuert SD (2008) Assessing the skill of an all-season statistical forecast model for the Madden-Julian oscillation. Mon Weather Rev 136:1940-1956

Kayano MT, Kousky VE (1999) Intraseasonal (30-60 day) variability in the global tropics: principal modes and their evolution. Tellus Ser Dyn Meteorol Oceanogr 51:373-386

Khairoutdinov MF, Randall DA (2001) A cloud resolving model as a cloud parameterization in the NCAR community climate system model: preliminary results. Geophys Res Lett 28:3617-3620

Khairoutdinov M, Randall D, DeMott C (2005) Simulations of the atmospheric general circulation using a cloud-resolving model as a superparameterization of physical processes. J Atmos Sci 62:2136-2154

Kikuchi K, Wang B (2009) Global perspective of the quasi-biweekly oscillation. J Clim 22:1340-1359

Kiladis GN, Hall-McKim EA (2004), Intraseasonal modulation of precipitation over the North American monsoon region. In: Proceedings of 15th symposium on global change and climate variations. Amer. Meteor. Soc., Seattle

Kim D, Sperber K, Stern W, Waliser D, Kang IS, Maloney E, Wang W, Weickmann K, Benedict J, Khairoutdinov M, Lee MI, Neale R, Suarez M, Thayer-Calder K, Zhang G (2009) Application of MJO simulation diagnostics to climate models. J Clim 22:6413-6436

Kim D, Sobel AH, Frierson DM, Maloney E, Kang IS (2011) A systematic relationship between intraseasonal variability and mean state bias in AGCM simulations. J Clim (in press)

Knutson TR, Weickmann KM (1987) 30-60 Day atmospheric oscillations: composite life cycles of convection and circulation anomalies. Mon Weather Rev 115:1407-1436 
Krishnamurti TN, Bhalme HN (1976) Oscillations of a monsoon system. 1. Observational aspects. J Atmos Sci 33:1937-1954

Lau WK-M, Waliser DE (2005), Intraseasonal variability in the atmosphere-ocean climate system. Springer, Heidelberg

Lee MI, Kang IS, Mapes BE (2003) Impacts of cumulus convection parameterization on aqua-planet AGCM Simulations of tropical intraseasonal variability. J Meteorol Soc Jpn 81:963-992

Lin J-L, Kiladis GN, Mapes BE, Weickmann KM, Sperber KR, Lin W, Wheeler MC, Schubert SD, Del Genio A, Donner LJ, Emori S, Gueremy J-F, Hourdin F, Rasch PJ, Roeckner E, Scinocca JF (2006) Tropical intraseasonal variability in 14 IPCC AR4 climate models. Part I: convective signals. J Clim 19:2665-2690

Lin JL, Lee MI, Kim D, Kang IS, Frierson DMW (2008a) The impacts of convective parameterization and moisture triggering on AGCM-simulated convectively coupled equatorial waves. J Clim 21:883-909

Lin JL, Mapes BE, Weickmann KM, Kiladis GN, Schubert SD, Suarez MJ, Bacmeister JT, Lee MI (2008b) North American monsoon and convectively coupled equatorial waves simulated by IPCC AR4 coupled GCMs. J Clim 21:2919-2937

Lorenz DJ, Hartmann DL (2006) The effect of the MJO on the North American monsoon. J Clim 19:333-343

Madden RA, Julian PR (1994) Observations of the 40-50-day tropical oscillation: a review. Mon Weather Rev 122:814-837

Magana V, Amador JA, Medina S (1999) The midsummer drought over Mexico and Central America. J Clim 12:1577-1588

Maloney ED, Esbensen SK (2003) The amplification of East Pacific Madden-Julian oscillation convection and wind anomalies during June-November. J Clim 16:3482-3497

Maloney ED, Esbensen SK (2007) Satellite and Buoy observations of boreal summer intraseasonal variability in the tropical Northeast Pacific. Mon Weather Rev 135:3-19

Maloney ED, Hartmann DL (2000a) Modulation of Eastern North Pacific hurricanes by the Madden-Julian oscillation. J Clim 13:1451-1460

Maloney ED, Hartmann DL (2000b) Modulation of hurricane activity in the Gulf of Mexico by the Madden-Julian oscillation. Science 287:2002-2004

Maloney ED, Shaman J (2008) Intraseasonal variability of the West African Monsoon and Atlantic ITCZ. J Clim 21:2898-2918

Maloney ED, Chelton DB, Esbensen SK (2008) Subseasonal SST variability in the tropical eastern north Pacific during boreal summer. J Clim 21:4149-4167

Martin ER, Schumacher C (2010), Modulation of Caribbean precipitation by the Madden-Julian oscillation. J Clim (in press)

Molinari J, Vollaro D (2000) Planetary- and synoptic-scale influences on eastern Pacific tropical cyclogenesis. Mon Weather Rev 128:3296-3307

Moorthi S, Suarez MJ (1992) Relaxed Arakawa-Schubert-a parameterization of moist convection for general-circulation models. Mon Weather Rev 120:978-1002

Mullen SL, Schmitz JT, Renno NO (1998) Intraseasonal variability of the summer monsoon over Southeast Arizona. Mon Weather Rev 126:3016-3035

Neale RB, Richter JH, Jochum M (2008) The impact of convection on ENSO: from a delayed oscillator to a series of events. J Clim 21:5904-5924

Nordeng TE (1994) Extended versions of the convective parametrization scheme at ECMWF and their impact on the mean and transient activity of the model in the tropics. ECMWF Tech. Memo 206

North GR, Bell TL, Cahalan RF, Moeng FJ (1982) Sampling errors in the estimation of empirical orthogonal functions. Mon Weather Rev 110:699-706

Numaguti AM, Takahashi M, Nakajima T, Sumi A (1995) Development of an atmospheric general circulation model. Clim Syst
Dyn Modell I-3 (T. Matsuno, Ed., Center for Climate System Research, 1-27)

Paegle JN, Byerle LA, Mo KC (2000) Intraseasonal modulation of South American summer precipitation. Mon Weather Rev 128:837-850

Rienecker MM, Suarez MJ, Todling R, Bacmeister JT, Takacs L, Liu H-C, Gu W, Sienkiewicz M, Koster RD, Gelaro R, Stajner I, Nielsen JE (2008) The GEOS-5 data assimilation systemdocumentation of versions 5.0.1, 5.1.0, and 5.2.0 Goddard Space Flight Center, Greenbelt, Maryland 20771

Roeckner E et al (1996) The atmospheric general circulation model ECHAM-4: model description and simulation of present-day climate, MPI Rep. 218

Saha S, Nadiga S, Thiaw C, Wang J, Wang W, Zhang Q, Van den Dool HM, Pan HL, Moorthi S, Behringer D, Stokes D, Pena M, Lord S, White G, Ebisuzaki W, Peng P, Xie P (2006) The NCEP climate forecast system. J Clim 19:3483-3517

Seo KH, Wang WQ (2010) The Madden-Julian oscillation simulated in the NCEP climate forecast system model: the importance of stratiform heating. J Clim 23:4770-4793

Serra YL, Kiladis GN, Hodges KI (2010) Tracking and mean structure of easterly waves over the intra-Americas Sea. J Clim 23:4823-4840

Simmons A, Uppala S, Dee D, Kobayashi S (2006) ERA-interim: new ECMWF reanalysis products from 1989 onwards. ECMWF, Shinfield Park, Reading

Slingo JM, Sperber KR, Boyle JS, Ceron JP, Dix M, Dugas B, Ebisuzaki W, Fyfe J, Gregory D, Gueremy JF, Hack J, Harzallah A, Inness P, Kitoh A, Lau WKM, McAvaney B, Madden R, Matthews A, Palmer TN, Park CK, Randall D, Renno N (1996) Intraseasonal oscillations in 15 atmospheric general circulation models: results from an AMIP diagnostic subproject. Clim Dyn 12:325-357

Slingo JM, Inness PM, Sperber KR (2005) Modeling. In: Lau WKM, Waliser DE (eds) Intraseasonal variability in the atmosphereocean climate system. Springer, Heidelberg, pp 361-388

Small RJ, De Szoeke SP, Xie S-P (2007) The Central American midsummer drought: regional aspects and large-scale forcing. J Clim 20:4853-4873

Small RJ, Xie S, Maloney E, de Szoeke SP, Miyama T (2011) Intraseasonal variability in the far-east pacific: investigation of the role of air-sea coupling in a regional coupled model Clim Dyn 36:867-890

Sperber KR, Gualdi S, Legutke S, Gayler V (2005) The MaddenJulian oscillation in ECHAM4 coupled and uncoupled general circulation models. Clim Dyn 25:117-140

Sultan B, Janicot S, Diedhiou A (2003) The West African monsoon dynamics. Part I: documentation of intraseasonal variability. J Clim 16:3389-3406

Thayer-Calder K, Randall DA (2009) The role of convective moistening in the Madden-Julian oscillation. J Atmos Sci 66:3297-3312

Tiedtke M (1989) A comprehensive mass flux scheme for cumulus parameterization in large-scale models. Mon Weather Rev 117:1779-1800

Tiedtke M (1993) Representation of clouds in large-scale models. Mon Weather Rev 121:3040-3061

Tokioka T, Yamazaki K, Kitoh A, Ose T (1988) The equatorial 30-60 day oscillation and the Arakawa-Schubert penetrative cumulus parameterization. J Meteorol Soc Jpn 66:883-901

US CLIVAR Madden-Julian Oscillation Working Group (2009) MJO simulation diagnostics. J Clim 22:3006-3030

Vintzileos A, Rienecker MM, Suarez MJ, Schubert SD, Miller SK (2005) Local versus remote wind forcing of the equatorial Pacific surface temperature in July 2003. Geophys Res Lett 32:L05702. doi:10.1029/2004GL021972 
Waliser DE (2006) Predictability of tropical intraseasonal variability. In: Palmer T, Hagedorn R (eds) Predictability of weather and climate. Cambridge University Press, Cambridge, p. 718

Wang WQ, Seo KH (2009) The Madden-Julian oscillation in NCEP coupled model simulation. Terres Atmos Oceanic Sci 20:713725

Wang WQ, Saha S, Pan HL, Nadiga S, White G (2005) Simulation of ENSO in the new NCEP coupled forecast system model (CFS03). Mon Weather Rev 133:1574-1593

Weare BC, Nasstrom JS (1982) Examples of extended empirical orthogonal function analyses. Mon Weather Rev 110:481-485

Wen M, Yang S, Higgins W, Zhang R (2011) Characteristics of the dominant modes of atmospheric quasi-biweekly oscillation over tropical-subtropical Americas. J Clim (in press)

Wu MLC, Schubert SD, Suarez MJ, Huang NE (2009) An analysis of moisture fluxes into the Gulf of California. J Clim 22:2216-2239

Xie S-P, Xu H, Kessler WS, Nonaka M (2005) Air-sea interaction over the Eastern Pacific Warm Pool: gap winds, thermocline dome, and atmospheric convection. J Clim 18:5-20

Zhang CD (2005) Madden-Julian oscillation. Rev Geophys 43:36
Zhang GJ, Mcfarlane NA (1995) Sensitivity of climate simulations to the parameterization of cumulus convection in the Canadian climate centre general circulation model. Atmos Ocean 33:407-446

Zhang GJ, Mu M (2005) Effects of modifications to the ZhangMcFarlane convection parameterization on the simulation of the tropical precipitation in the national center for atmospheric research community climate model, version 3. J Geophys Res 110:D09109

Zhang CD, McGauley M, Bond NA (2004) Shallow meridional circulation in the tropical eastern Pacific. J Clim 17:133-139

Zhao M, Held IM (2010) An analysis of the effect of global warming on the intensity of Atlantic hurricanes using a GCM with statistical refinement. J Clim 23:6382-6393

Zhao M, Held IM, Lin SJ, Vecchi GA (2009) Simulations of global hurricane climatology, interannual variability, and response to global warming using a 50-km resolution GCM. J Clim 22:6653-6678

Zhao M, Held IM, Vecchi GA (2010) Retrospective forecasts of the hurricane season using a global atmospheric model assuming persistence of SST anomalies. Mon Weather Rev 138:3858-3868 